\title{
Baumwolle, Elfenbein und Glasperlen. Perspektiven österrei- chischer Reisender auf die Errichtung eines „informal empire“ im Sudan des 19. Jahrhunderts
}

\author{
Florian Ambach \\ Kerngebiet: Österreichische Geschichte \\ eingereicht bei: Ass.-Prof. ${ }^{\text {in }}$ Dr. ${ }^{\text {in }}$ Ellinor Forster \\ eingereicht im: WiSe 2019/20 \\ Rubrik: Bachelor-Arbeit
}

\begin{abstract}
Cotton, Ivory and Glass Beads. Perspectives of Austrian Travellers on the Establishment of an "Informal Empire" in 19th Century Sudan

The following article examines travel accounts of explorers, travellers and officials close to the Habsburg Monarchy. It focusses on the economic aspects of the 19th century Austrian presence in Sudan. As will be shown, several Austrians attempted to engage in local trade in ways that sought to establish an "informal empire".
\end{abstract}

\section{Einleitung}

Gegen Ende des 18. Jahrhunderts rückte Ägypten verstärkt in den Fokus Frankreichs und des Vereinigten Königreichs. Diese beiden rivalisierenden Kolonialmächte waren es, die nach dem Niedergang der spanischen, portugiesischen und niederländischen Kolonialreiche bestimmenden Einfluss auf Kolonialismus und Imperialismus in Afrika nahmen.' Beide hatten gegen Ende des 18. Jahrhunderts Kolonien in den Amerikas

Im Unterschied zu Asien und den Amerikas, wo die europäischen Mächte sukzessive von einem über die Ostindien- und Westindienkompanien in die Wege geleiteten „informal empire" zu einer direkten Präsenz im Sinne des "formal empire" übergegangen waren, war der europäische Zugriff auf Afrika bis ungefähr zur Mitte des 19. Jahrhunderts noch weitgehend auf die Küstengebiete beschränkt, bevor ab den 1880er-Jahren mit dem Scramble for Africa und der Aufteilung Afrikas ein entfesselter Imperialismus zur außenpolitischen Maxime zahlreicher europäischer Staaten wurde. Davor waren die Küsten rege Kontaktzonen, an denen Waren gehandelt, umgeschlagen und weitertransportiert wurden. Auch der Handel mit Menschen, die zur Arbeit auf Plantagen gezwungen wurden, war Teil der europäischen Expansion und wurde sowohl an der Atlantikküste als auch an den ostafrikanischen Küsten betrieben. Im Inneren des Kontinents konnten sich verschiedene afrikanische Reiche 
verloren - das Vereinigte Königreich durch die Unabhängigkeitserklärung der Vereinigten Staaten von Amerika (1776), Frankreich durch die Haitianische Revolution (17911804). Ägypten nahm in den Planungen Frankreichs eine zentrale Rolle ein, da mit der Besetzung des Landes die Hoffnung einherging, die britische Vormachtstellung im Mittelmeer zu brechen. Zudem wollte Frankreich mit der kolonialen Inbesitznahme Ägyptens die britischen Kommunikationslinien nach Indien abschneiden, um die Hegemonie der Royal Navy auf den Weltmeeren zu beenden. Das mit Napoleons Ägyptenfeldzug 1798 begonnene Projekt erwies sich allerdings als nahezu undurchführbar und musste deshalb bereits 1801 aufgegeben werden. ${ }^{2}$

Das nach dem Rückzug Frankreichs entstandene Machtvakuum wurde von dem albanischen Offizier Muhammad Ali Pascha (1770-1849)33 gefüllt, der 1801 von der Hohen Pforte zum Gouverneur Ägyptens ernannt wurde und sich ab 1805 als Vizekönig (wāli) ansprechen ließ. Zwischen 1820 und 1822 führte Muhammad Ali mehrere Eroberungsfeldzüge im Gebiet des heutigen Sudan durch. ${ }^{4}$ Damit wollte er einerseits die Herrschaft der bereits 1811 aus dem ägyptischen Kernland vertriebenen Mameluken endgültig brechen, die südlich von Ägypten ein neues Reich gründen wollten. ${ }^{5}$ Noch wichtiger war ihm aber die Beherrschung dieser Regionen aufgrund der dort vorkommenden Rohstoffe. Muhammad Ali konnte Ägypten sukzessive aus dem Osmanischen Reich loslösen ${ }^{6}$ - und suchte im Zuge dieses Desintegrationsprozesses nach neuen strategischen Partnern in Europa, wodurch er sich Stabilität und steigenden Einfluss auf dem globalen politischen Parkett erhoffte. Darüber hinaus sollte durch den Austausch mit europäischen Fachleuten aus den Bereichen Infrastruktur, Logistik, Handel, Industrie und Wissenschaft Pionierarbeit für die wirtschaftliche Erschließung des Sudan geleistet werden. Das neueroberte Gebiet mit seinen vielfältigen Ressourcen sollte zum finanziellen Reservoir für ein umfassendes Modernisierungsprojekt werden.?

Dazu wandte sich Muhammad Ali 1834 mit der Bitte nach Entsendung von Bergbauexperten an die österreichische Regierung. Schließlich wurde der Salzburger Montanist Joseph Russegger zum Leiter eines Expeditionsteams ernannt, das den Sudan nach Bodenschätzen und Rohstoffen durchkämmen sollte. ${ }^{8}$ In den Folgejahren drangen europäische Handelsreisende, Naturforscher*innen und Entdecker*innen immer tiefer in

noch lange gegen Vorstöße der Europäer*innen zur Wehr setzen. Die einzigen Ausnahmen bildeten die 1652 von der V.O.C. errichtete Kapkolonie, die 1806 in britischen Besitz überging, und Algerien, wo sich Frankreich ab 1830 dauerhaft festzusetzen begann: Wolfgang Reinhard, Die Unterwerfung der Welt. Globalgeschichte der europäischen Expansion 1450-2015, München 2016, S. 901-975. Zu den unterschiedlichen Stufen der Interaktion und den Konzepten "formal empire“ und „informal empire“: Jürgen Osterhammel, Kolonialismus. Geschichte Formen - Folgen, München 1995 und Reinhard Wendt, Vom Kolonialismus zur Globalisierung. Europa und die Welt seit 1500, Paderborn-München-Wien-Zürich 2007, S. 152-159.

2 Jürgen Osterhammel, Die Verwandlung der Welt. Eine Geschichte des 19. Jahrhunderts, München 2016², S. 575577.

3 Khaled Fahmy, Mehmed Ali. From Ottoman Governor to Ruler of Egypt, Oxford 2008.

$4 \quad$ Mario Gritsch, Die Beziehungen Österreich-Ungarns zum ägyptischen Sudan. Die staatlichen, kirchlichen sowie privaten Interessen und Unternehmungen in diesem Raume, phil. Diss. Wien 1975, S. 18-23.

5 Richard Hill, Egypt in the Sudan 1820-1881, London 1959, S. 7-8.

6 Osterhammel, Die Verwandlung der Welt, S. 640-643.

$7 \quad$ Florian Krobb, "The starting point for the civilisation of the Dark Continent." Austrians in the Sudan: Ernst Marno and Rudolf Slatin as Agents of African Conquest, in: Austrian Studies 20 (2012), S. 142-160, hier S. 143.

8 Gritsch, Die Beziehungen Österreich-Ungarns zum ägyptischen Sudan, S. 34-35. 
den afrikanischen Kontinent vor und sahen die reichen Vorkommen an Bodenschätzen als Chance für die Abwicklung ihrer eigenen Geschäfte.

In der vorliegenden Arbeit sollen die kolonialen Vorstellungen jener aus der Habsburgermonarchie stammenden Akteure untersucht werden, die sich im Zeitraum 1830 bis 1880 im Sudan aufhielten. Neben dem bereits erwähnten Russegger zählen dazu der aus Böhmen stammende Kaufmann Ignaz Pallme, der württembergische Naturforscher Theodor von Heuglin, der als Sekretär des ersten Konsuls von Khartum, Konstantin Reitz, tätig war, und Martin Ludwig Hansal, der im Rahmen der Apostolischen katholischen Mission für Zentralafrika im Sudan wirkte. All diese Akteure hinterließen Reiseberichte, die zwischen den 1840er- und 1860er-Jahren veröffentlicht wurden und als Quellengrundlage für diese Arbeit dienen. Um die verschiedenen Reiseberichte in Bezug auf die wirtschaftlichen Potentiale und die politische Durchsetzung von Handelsprivilegien zu untersuchen, wurde eine analytische Trennung nach Rohstoffen und Wirtschaftszweigen gewählt. Dieser Ansatz erlaubt es, die zu unterschiedlichen Zeitpunkten und unter verschiedenen Blickwinkeln verfassten Reiseberichte gemeinsam zu analysieren.

Durchaus können - so die These der Arbeit - die von den österreichischen oder im Dienst der Habsburgermonarchie tätigen Akteuren entworfenen Nutzungsszenarien für den ägyptischen Sudan und die seit der Gründung des k. u. k. Konsulats von Khartum im Jahr 1850 tatsächlich ausgeübte Herrschaft der k. u. k. Beamtenschaft und der unter ihrem Schutz stehenden europäischen Community im Sudan als „informal empire" angesehen werden.

\section{Forschungsstand}

Dass die Habsburgermonarchie nie Kolonien besessen hatte, war lange die "Lebenslüge der Zweiten Republik" . Auch in aktuellen Überblickswerken zur Österreichischen Geschichte ist die Partizipation der Habsburgermonarchie an Kolonialismus und Imperialismus ein unterrepräsentiertes Thema. Nur zaghaft hat die jüngere Forschung von der als unpolitisch bezeichneten Entdeckungsgeschichte ${ }^{10}$ Abstand genommen und Österreichs Rolle im System des kollektiven „informellen Imperialismus“11, der infolge des Wiener Kongresses das Europäische Konzert bestimmte, zu definieren versucht -, ohne dass diese Position allerdings allgemeiner Konsens geworden wäre. ${ }^{12}$ Die Tatsache, dass die Habsburgermonarchie mit Triest über einen direkten Zugang zum Meer verfügte und mit den europäischen Seehandelsmächten in Konkurrenz treten wollte, war entscheidender Motor für die Gründung von österreichischen Orient- und Ostindienkompanien im 18. Jahrhundert, die allerdings nur begrenzten Erfolg hatten. Die

9 Walter Sauer, Auf dem Weg zu einer Kolonialgeschichte Österreichs, in: Österreich in Geschichte und Literatur 55 (2011), Heft 1, S. 2-6, hier S. 3.

10 Darunter am prominentesten Hugo Hassinger, Österreichs Anteil an der Erforschung der Erde. Ein Beitrag zur Kulturgeschichte Österreichs, Wien 1949.

11 Wendt, Vom Kolonialismus zur Globalisierung, S. 154-155.

12 Walter Sauer, Schwarz-Gelb in Afrika. Habsburgermonarchie und koloniale Frage, in: Walter Sauer (Hrsg.), k. u. k. kolonial. Habsburgermonarchie und europäische Herrschaft in Afrika, Wien-Köln-Weimar 2002, S. 17-78, S. 18. 
Hafenstadt Triest erfuhr nach der napoleonischen Herrschaft verschiedene Ausbauphasen, durch die der Handel mit Übersee intensiviert wurde. Insbesondere Ägypten wurde ein wichtiger Partner im österreichischen Außenhandel.

Arno Strohmeyer hat der österreichischen Geschichtsforschung nach 1945 eine sukzessive Erweiterung des zu untersuchenden Raums nachgewiesen. Während in der unmittelbaren Nachkriegszeit eine Konzentration auf das Territorium der Zweiten Republik festzustellen war, kamen in den 1960er- und 1970er-Jahren das Gebiet der Habsburgermonarchie, des Heiligen Römischen Reichs, in den 1980er-Jahren Europa, europäische Mesoregionen und das habsburgische Imperium hinzu. ${ }^{13}$ Dieses Konzept sei aber "offen gegenüber weiteren Raumkategorien“, wobei die österreichische Geschichte insbesondere um globale Räume erweitert werden müsse. ${ }^{14}$

Die erste Publikation zum Themenkomplex der österreichischen Präsenz im Sudan legte Mario Gritsch 1975 mit seiner Dissertation vor..$^{15}$ Darin lieferte er eine chronologische Übersicht über das Thema und widmete sich den einzelnen Akteur*innen, deren Reiserouten und Aktivitäten er nachzeichnete. Gritschs Dissertation blieb in der Landschaft der österreichischen Geschichtsforschung relativ lange unbemerkt. Michael Zach, der sich mit den Beziehungen Österreichs zum afrikanischen Kontinent beschäftigt, legte 1985 eine Monografie über die österreichische Präsenz im Sudan vor. ${ }^{16} 1993$ widmete sich Rudolf Agstner der 1850 erfolgten Gründung des k. u. k. Konsulats von Khartum. ${ }^{17}$ Einen bedeutenden Beitrag zur Neubewertung österreichischer Kolonialpolitik lieferte Walter Sauer in seinem 2002 erschienenen Sammelband, in dem erstmals auch verflechtungsgeschichtliche Ansätze verwendet wurden. ${ }^{18}$ Robert-Tarek Fischers Monografie, die einen umfassenden Längsschnitt vom 16. bis ins 20. Jahrhundert zum österreichischen Engagement in Afrika und Asien liefert, ist ebenfalls in das Forschungsparadigma der sukzessiven Erweiterung des zu untersuchenden Raumes einzureihen. ${ }^{19}$

Nachdem die österreichische Präsenz im Sudan bereits von verschiedenen Perspektiven behandelt worden ist, soll nun versucht werden, die Ideen und Pläne der österreichischen Reisenden zu beleuchten und damit Strohmeyers Ruf nach einer Öffnung der österreichischen Geschichte hin zu globalen Verflechtungen zu folgen.

13 Arno Strohmeyer "Österreichische" Geschichte der Neuzeit als multiperspektivische Raumgeschichte, in: Martin Scheutz/Arno Strohmeyer (Hrsg.), Was heißt "Österreichische“ Geschichte? Probleme, Perspektiven und Räume der Neuzeitforschung (Wiener Schriften zur Geschichte der Neuzeit 6), Innsbruck-Wien-Bozen 2008, S. 167-197, hier S. 170-185.

14 Strohmeyer, „Österreichische” Geschichte, S. 185.

15 Mario Gritsch, Die Beziehungen Österreich-Ungarns zum ägyptischen Sudan. Die staatlichen, kirchlichen sowie privaten Interessen und Unternehmungen in diesem Raume, phil. Diss. Wien 1975.

16 Michael Zach, Österreicher im Sudan von 1820 bis 1914, Wien 1985.

17 Rudolf Agstner, Das k.k. (k.u.k.) Konsulat für Central-Afrika in Khartoum 1850-1885, Kairo 1993.

18 Walter Sauer (Hrsg.), k. u. k. kolonial. Habsburgermonarchie und europäische Herrschaft in Afrika, Wien-KölnWeimar 2002.

19 Robert-Tarek Fischer, Österreich im Nahen Osten. Die Großmachtpolitik der Habsburgermonarchie im Arabischen Orient 1633-1918, Wien-Köln-Weimar 2006. 


\section{Quellen}

Als Quellenbasis für die vorliegende Arbeit dienen die Reiseberichte, die von den gewählten Akteuren veröffentlicht wurden. Neben Routenbeschreibungen finden sich darin auch historische, wirtschaftliche, naturwissenschaftliche, ethnografische, geologische und klimatologische Informationen, wobei in der vorliegenden Arbeit eine analytische Trennung nach Rohstoffen vorgenommen wird, um den wirtschaftlichen Aspekten der Reiseberichte nachzuspüren. Der Sudan trat durch die Publikationen in das Bewusstsein eines kleinen Kreises wirtschaftlicher Interessent*innen, der primär im Umfeld des maritimen Interessenskomplexes in Triest zu verorten ist. ${ }^{20}$

Nachdem sich im Zuge der Griechischen Revolution die Beziehungen zwischen Ägypten und der Habsburgermonarchie intensiviert hatten, ${ }^{21}$ war der diplomatische Rahmen für die 1834 geäußerte Bitte Muhammad Alis an die österreichische Regierung um Entsendung von Bergbauexperten gegeben. Unter Vermittlung Metternichs wurde der Salzburger Montanist Joseph Russegger (1802-1863) zum Leiter eines Expeditionsteams ernannt, welches vollumfänglich vom ägyptischen Vizekönig finanziert wurde und im Januar 1836 im Hafen von Triest seine Reise antrat.22 In Athen nahm Russegger Kontakt zu Anton Prokesch Ritter von Osten (1795-1876) - einem österreichischen Diplomaten und Orientalisten der ersten Stunde - auf, der sich für eine Intensivierung des Handels zwischen Ägypten und Österreich starkmachte. ${ }^{23}$ Nach Abschluss seiner Expedition bereiste Russegger Europa und kehrte im Februar 1841 nach Wien zurück. Russegger, der sein siebenbändiges Reisewerk Kaiser Ferdinand I. (1793-1875) widmete, zeigte sich stolz „ „einer Nation und einem Lande anzugehören, dessen Herrscher seine Beamten in die fernsten Theile der Erde sendet, um den Weg wissenschaftlicher Forschung zu gehen"24. Das Werk ist chronologisch angelegt und enthält im Anhang ausführliches Kartenmaterial sowie Datenkorpora über Niederschlag, Bodenbeschaffenheit und Höhenprofil der bereisten Regionen. ${ }^{25}$

Ignaz Pallme (1806-1877), der aus einer nordböhmischen Glaswarenhändlerfamilie stammte, bereiste nach der 1832 erfolgten Gründung eines Handelshauses in Kairo von Dezember 1837 bis Juli 1839 den Sudan. Anders als Russegger war Pallme nicht im Auftrag der Regierung unterwegs, sondern in privatem Interesse, um nach profitablen Geschäften Ausschau zu halten. Dennoch war er von den k. u. k. Behörden vor Ort

20 Alison Frank, Continental and Maritime Empires in an Age of Global Commerce, in: East European Politics and Societies 25 (2011), Heft 4, S. 779-784.

21 Es kam wiederholt zu diplomatischen Geschenkaustauschen. So ließ der ägyptische Vizekönig Muhammad Ali aus dem Inneren Afrikas eine Giraffe herbeischaffen und nach Triest verschiffen. Die Giraffe überlebte die Überfahrt nicht, dennoch wurde die Geste des Vizekönigs von Kaiser Franz I. sehr geschätzt und zum Dank wurden 17 Kisten österreichischer Luxusartikel nach Alexandria geschickt. Insbesondere die Spirituosen fanden das Wohlgefallen des Vizekönigs: Fischer, Österreich im Nahen Osten, S. 78-79.

22 Philipp Weingartshofer, Imperialismus-Strategien am Beispiel der Österreicher im Sudan. Das Zusammenspiel kolonialer Akteure in Peripherie und Metropole am Beispiel der Österreicher im Sudan im 19. Jahrhundert, phil. Dipl. Wien 2013, S. 91-92.

23 Anton von Prokesch, Erinnerungen aus Aegypten und Kleinasien, Bd. 2, Wien 1830, S. 152.

24 Joseph Russegger, Reisen in Europa, Asien und Afrika, mit besonderer Rücksicht auf die naturwissenschaftlichen Verhältnisse der betreffenden Länder, Bd. 1/1, Stuttgart 1841, S. 6.

25 Joseph Russegger, Reisen in Europa, Asien und Afrika, mit besonderer Rücksicht auf die naturwissenschaftlichen Verhältnisse der betreffenden Länder, 7 Bde., Stuttgart 1841-1849. 
abhängig, insbesondere vom Generalkonsulat in Alexandria, welches die österreichischen Handelsaktivitäten im Mittelmeerraum und in der Levante protegierte. ${ }^{26}$ Sein 1843 veröffentlichtes Reisewerk ${ }^{27}$ ist in 19 thematisch gegliederte Kapitel unterteilt. 1850 bewarb sich Pallme für das neu geschaffene Konsulat in Khartum und legte seine Pläne schriftlich vor, doch nicht er bekam den Posten, sondern der aus Württemberg stammende Baron Johann Wilhelm von Müller (1824-1866). Nach dessen Zögern wurde Konstantin Reitz (1817-1853) aus Hessen für die Stelle bestimmt. ${ }^{28}$

Konstantin Reitz spielte eine wichtige Rolle in der Erwirkung von Handelsprivilegien für europäische Händler ${ }^{29}$ im Sudan und unternahm eine ausgedehnte Reise nach Abessinien. Er starb am 26. Mai 1853 in Doka auf der Rückreise. ${ }^{30}$ Er selbst hinterließ keine Reiseberichte, wohl aber der thüringische Naturforscher Alfred Edmund Brehm (18291884) ${ }^{31}$, der Reitz nach Khartum begleitete, sowie der württembergische Naturforscher Theodor von Heuglin (1824-1876), der ihm als Sekretär zur Seite gestellt wurde.

Nach Reitz' Tod übernahm von Heuglin seinen Posten, doch aufgrund dessen fast durchgängiger Abwesenheit verwaiste das Konsulat zusehends. ${ }^{32} 1857$ wurde er zusammen mit dem Vizeadmiral der österreichisch-ungarischen Kriegsmarine, Wilhelm von Tegetthoff (1827-1871), von Erzherzog Ferdinand Maximilian (1832-1867) mit einer Geheimmission beauftragt. Sie sollten ausloten, ob sich die Insel Sokotra im Golf von Aden für eine koloniale Inbesitznahme eignete. Das Unternehmen ist in die Pläne des "maritimen Interessenskomplexes" im Umfeld des Triester Bankiers Pasquale Revoltella (1795-1869) einzuordnen, der zusammen mit dem Erzherzog eine parallele Außenpolitik verfolgte, von dessen Plänen weder Kaiser Franz Joseph I. noch dessen Minister wussten. ${ }^{33}$ Der Geheimauftrag wurde aber aufgedeckt und verpuffte wirkungslos. ${ }^{34}$ Heuglin beschrieb in seinem ersten Werk von 1857 die Reisen, die er in der Eigenschaft als Sekretär des Konsuls von Khartum Reitz unternommen hatte. ${ }^{35} \mathrm{Im}$ zweiten Werk von 1869 berichtete er über seine Reise von 1862 bis 1864, die er als

26 Weingartshofer, Imperialismus-Strategien, S. 89.

27 Ignaz Pallme, Beschreibung von Kordofan und einigen angränzenden Ländern nebst einem Ueberblick über den dasigen Handel, die Sitten und Gebräuche der Einwohner und die unter der Regierung Mehemed Alis stattgefundenen Sklavenjagden, Stuttgart-Tübingen 1843.

28 Zach, Ignaz Pallme, S. 79-82.

29 Hier und im Folgenden wird der Begriff "Händler" verwendet, eine Partizipation von Frauen am Sudanhandel ist zwar nicht auszuschließen, in der Literatur sowie im untersuchten Quellenkorpus ließen sich jedoch keine expliziten Belege für die Beteiligung von Frauen am Handel im Sudan finden. Eine geschlechtergeschichtliche Untersuchung der Rolle von (europäischen und nicht-europäischen) Frauen in der europäischen Community im Sudan, die fast ausschließlich aus Männern bestand, bleibt ein Forschungsdesiderat. Auch die romantisierenden, exotisierenden und z. T. auch bestialisierenden Bilder, mit denen die Reisenden aus Europa ägyptische, türkische, arabische, sudanesische und äthiopische Frauen beschrieben, verdienen eine nähere Untersuchung.

30 Deutsch, Die effektiven Konsuln Österreich (-Ungarns) von 1825-1918, S. 564-565.

31 Alfred Edmund Brehm, Reiseskizzen aus Nord-Ost-Afrika oder den unter egyptischer Herrschaft stehenden Ländern Egypten, Nubien, Sennahr, Rosseeres und Kordofahn, gesammelt auf seinen in den Jahren 1847 bis 1852 unternommenen Reisen, 3 Bde., Jena 1855.

32 Gritsch, Die Beziehungen Österreich-Ungarns zum ägyptischen Sudan, S. 101-104.

33 Sauer, Schwarz-Gelb in Afrika, S. 44

34 Gerald Colloseus, Ein österreichisches Schicksal? Analyse von Kolonialprojekten am Beispiel der Mission Tegetthoffs und Heuglins ins Rote Meer 1857/58, Dipl. Wien 2008

35 Theodor von Heuglin, Reisen in Nord-Ost-Afrika. Tagebuch einer Reise von Chartum nach Abyssinien mit besonderer Rücksicht auf Zoologie und Geographie unternommen in dem Jahre 1852 bis 1853. Mit einer Karte, einem Gebirgs-Durchschnitte und 3 Bildern, Gotha 1857. 
freischaffender Naturforscher angetreten hatte. ${ }^{36}$ Darin bewertete er - da er sich inzwischen mit den k. u. k. Behörden überworfen hatte - die Aktivitäten der europäischen Händler am Weißen Nil durchaus kritisch.

Martin Ludwig Hansal (1823-1885) aus Mähren schloss sich 1853 der katholischen Mission für Zentralafrika an und begleitete deren Leiter Ignaz Knoblecher (1819-1858) auf Reisen entlang des Weißen Nils. In Gondokoro betreute er als Lehrer die Missionsschule, bevor er 1863 das Konsulat von Khartum übernahm. Die Schließung des Konsulats in Khartum nach der Eröffnung des Suezkanals und die Gründung zweier neuer Konsulate in Aden und Sansibar zeigen, dass der Sudan für die österreichischen Kolonialambitionen kaum mehr eine Rolle spielte. Dennoch erklärte sich Hansal bereit, das Konsulat ehrenamtlich weiterzuführen. Am 26. Jänner 1885 wurde Khartum von den Truppen des Mahdi eingenommen. Hansal wurde mit einer Lanze erstochen, enthauptet, sein Leichnam verkohlt und anschließend in den Nil geworfen. ${ }^{37}$ Der ursprünglich für britische Kolonialbeamte verwendete Begriff man on the spot trifft am ehesten auf Hansal zu, der über einen Zeitraum von über dreißig Jahren im Sudan war. Er stand während seines Aufenthalts im Sudan in Briefkontakt mit seinem einstigen Lehrerkollegen Franz Xaver Imhof, der die Briefe in zwei Bänden (1855/56) herausgab. ${ }^{38}$

\section{Methodik}

Das zu untersuchende Gebiet, das im heutigen Sudan, Südsudan und in Teilen Äthiopiens zu lokalisieren ist, soll als Verflechtungsraum verstanden werden, in dem zahlreiche, aus unterschiedlichen Kontexten stammende Akteur*innen ihre Interessen durchzusetzen versuchten. Ziel soll es sein, die vielfältigen Beziehungen und Netzwerke kolonialer Lobbys, staatlicher Akteur*innen und privater Reisender aufzuzeigen und in den Gesamtzusammenhang des österreichischen Imperialismus einzuordnen. Die Argumentation beruht auf der Annahme Walter Sauers, die Habsburgermonarchie sei, ohne jemals über eigenen Kolonialbesitz zu verfügen, Mitträger eines „kollektiven Imperialismus ${ }^{\prime 39}$ im Concert europèen gewesen. ${ }^{40}$ Grundsätzlich, so die These, waren es

36 Theodor von Heuglin, Reise in das Gebiet des Weissen Nil und seiner westlichen Zuflüsse in den Jahren 18621864, Leipzig-Heidelberg 1869.

37 Gerhard Jandl, "Österreichs Name ist der wohlklingendste im ganzen Sudan“. Die Österreichische Mission in Zentralafrika (1848-1916) und die Beteiligung von katholischen Couleurstudenten (Tradition und Zukunft 17), Wien 2019, S. 55.

38 Franz Xaver Imhof (Hrsg.), Neueste Briefe aus Chartum in Central-Afrika, geschrieben von Martin Hansal, gewesenem Lehrer an der Pfarrhauptschule zu Maria Geburt am Rennwege in Wien, derzeit Lehrer der Negerjugend und Sekretär des hochwürdigen Herrn Pro-Vikars Dr. Knoblecher, Chefs der katholischen Mission für Mittel-Afrika zu Chartum, an seinen Freund Franz Xaver Imhof, Lehrer an der Pfarrhauptschule zu Maria Geburts am Rennwege in Wien, Wien 1855; Franz Xaver Imhof (Hrsg.), Fortsetzung der neuesten Briefe aus Chartum in Central-Afrika, geschrieben von Martin Hansal, gewesenem Lehrer an der Pfarrhauptschule zu Maria Geburt am Rennwege in Wien, derzeit Lehrer der Negerjugend und Sekretär des hochwürdigen Herrn Pro-Vikars Dr. Knoblecher, Chefs der katholischen Mission für Mittel-Afrika zu Chartum, Wien 1856.

39 Der Begriff wurde geprägt von George Neville Sanderson, British Informal Empire, Imperial Ambitions, Defensive Strategies, and the Anglo-Portuguese Congo Treaty of February 1884, in: Stig Förster/Wolfgang J. Mommsen/ Ronald Robinson (Hrsg.), Bismarck, Europe, and Africa. The Berlin Africa Conference 1884-1885 and the Onset of Partition, London 1988, S. 189-214.

40 Sauer, Schwarz-Gelb in Afrika. S. 18. 
die vor Ort befindlichen Akteur*innen, die die staatliche Handels- und Außenpolitik zu ihren Gunsten beeinflussen wollten. ${ }^{41}$ Einen umfassenden kolonialen Plan hat es von staatlicher Seite kaum gegeben. Die von Handelsminister Karl Ludwig von Bruck (1798-1860) eingeleitete Politik ${ }^{42}$ und die in seine Amtszeit fallende Gründung des Konsulats in Khartum sind als die ernsthaftesten Überlegungen, die in die Richtung koIonialer Zielsetzungen zeigen, zu betrachten. Erst die Geheimmission von 1857 enthielt konkrete Pläne, Inseln im Roten Meer zu erwerben. Nicht einmal das Außen- oder Handelsministerium wusste von dieser Mission und es wird deutlich, dass derartige koloniale Pläne im offiziellen Staatsapparat nicht auf fruchtbaren Boden gefallen wären.

Im Zuge der Untersuchung kommt den gewählten Akteuren eine wichtige Rolle zu. Sie fungierten als Scharniere, in denen Einzelstränge globaler Verbindungszusammenhänge zusammenliefen. ${ }^{43}$ Diese Verflechtungen zeigen sich besonders deutlich am Beispiel von Personen, die verschiedene Orte bereisten sowie von Waren, die von A nach B transportiert wurden. Darüber hinaus wurde Wissen transferiert, wodurch es zu einem Ideenaustausch kam. Gedankliche Konzepte und Know-how gelangten durch europäische Reisende in den Sudan, wo die Europäer*innen diese an lokale Verhältnisse anpassen mussten. Gleichzeitig nahmen die Europäer*innen Ideen und Denktraditionen aus dem Sudan mit. Meistens ging der von den Reisenden angestoßene Vergleich zwischen europäischem und ägyptischem/sudanesischem Know-how mit den Gegensatzpaaren zivilisiert-unzivilisiert, kultiviert-primitiv einher. ${ }^{44}$

Anhand der Thematisierung des wirtschaftlichen Potentials verschiedener Rohstoffe durch die Reisenden können die vielfältigen Verflechtungen zwischen Österreich und dem Sudan gut aufgezeigt werden - und zwar in personeller, technologischer und logistischer Hinsicht. Das heißt konkret: Welche Personen kamen für die Anpflanzung, die Gewinnung, die Verarbeitung, den Transport und den Vertrieb der Rohstoffe infrage? Gab es unter den lokalen Machthabern Kollaborateure, die ins Netzwerk miteinbezogen wurden? Welche Anbau- und Verarbeitungsmethoden wurden angewandt? Kam es dabei zu einem Wissenstransfer zwischen dem Sudan, Ägypten und Österreich? Welche Strategien wurden entworfen, um den hohen Zöllen zu entgehen? Und letztlich: Wer profitierte davon - und wer nicht?

41 Aufgrund der schwierigen Transportbedingungen und der hohen Zölle profitierte die Habsburgermonarchie kaum von einem Engagement im Sudan. Lediglich die vor Ort befindlichen Kaufleute konnten im Zwischenhandel beträchtliche Gewinne lukrieren: Weingartshofer, Imperialismus-Strategien, S. 103-104.

42 Thomas J. Hagen, Österreichs Mitteleuropa 1850-1866. Die Wirtschafts-, Währungs- und Verkehrsunion des Karl Ludwig Freiherrn von Bruck (Historische Studien 507), Husum 2015.

43 Roland Wenzlhuemer, Globalgeschichte schreiben. Eine Einführung in 6 Episoden, Konstanz-München 2017, S. 149.

44 Die lokale Bevölkerung wurde von den meisten Reisenden als unzivilisiert (Russegger, Reisen, Bd. 1/1, S. 118; Pallme, Beschreibung von Kordofan, S. 67-68) und geschichtslos (Pallme, Beschreibung von Kordofan, S. 7) charakterisiert. Demgegenüber wurde das christliche Europa als Mittelpunkt der Zivilisation beschrieben (Russegger, Reisen, Bd. 1/1, S. 118-119). An zahlreichen Stellen in den Reiseberichten wurde die Notwendigkeit eines katholischen Missionsprojektes in den südlichen Gebieten des Sudan hervorgehoben (Russegger, Reisen, Bd. 2/2, S. 32; Pallme, Beschreibung von Kordofan, S. 117). Der von der moralischen Überlegenheit und dem technologische Fortschritt Europas überzeugte Russegger sah in diesen Gründen eine Berechtigung zur "Zivilisierung" und Beherrschung anderer Länder (Russegger, Reisen, Bd. 2/1, S. 8.). Eine Ausnahme bildete die Beurteilung des Alten Ägyptens, dessen Kultur insbesondere von Russegger in den höchsten Tönen gelobt wurde (Russegger, Reisen, Bd. 1/1, S. 122-123). 


\section{Perspektiven österreichischer Reisender auf wirtschaftliche Potentiale des Sudan}

5.1 "Ein wahres Eldorado"?45 Österreichische Montanisten auf der Suche nach Gold in den Mondbergen

Am 11. Dezember 1836 erhielt der von Triest aus angereiste Joseph Russegger die Bewilligung des Vizekönigs, nach Nubien, in den Sudan und in die südlich an den ägyptischen Machtbereich grenzenden Territorien zu reisen, um nach Gold zu suchen. ${ }^{46}$ Muhammad Ali und sein Beratungsstab gingen fest davon aus, „der Nil entspringe mit zwei Armen aus grossen See'n, die sich am Rande einer Gebirgskette befinden, deren Berge hoch in die Wolken ansteigen" ${ }^{\prime 47}$. Diese Annahme gründete auf der bereits von Ptolemäus vermuteten Existenz eines äquatornahen Gebirges (Montes Lunae), in dem die Arme des Blauen wie des Weißen Nils entspringen würden. Diese von islamischen Gelehrten tradierte Theorie führte dazu, dass das Mondgebirge noch im 19. Jahrhundert einen „zwiespältigen Status“ zwischen Realität und Fantasie hatte. ${ }^{48}$

Das im Inneren Afrikas vermutete Gold sollte die finanzielle Basis für das Modernisierungsprojekt des Vizekönigs bilden, für das zunächst noch europäische Produkte importiert werden mussten. Falls Gold in großen Mengen gefunden würde, so die Mutmaßung Russeggers, würde dieses in Austausch mit europäischen Rohstoffen und Produkten nach Europa abfließen. Blei, Eisen und Kohle, "so nöthig für seine Flotte, seine Landarmee, seine Fabriken, musste er für enormes Geld aus Europa beziehen"49. Als mögliche Zwischenhändler mag Russegger die in Alexandria und Kairo ansässigen Händler im Blick gehabt haben, zumal es allein dort bereits zu Beginn der 1820er-Jahre 28 österreichische Handelshäuser gab. ${ }^{50}$

Russegger erreichte am 13. März 1837 das am Zusammenfluss von Weißem und Blauem Nil liegende Khartum. ${ }^{51}$ Die Stadt war erst 1821 im Zuge der ägyptischen Eroberung errichtetet worden und stieg bereits anderthalb Jahrzehnte später zu einem Knotenpunkt des Handels zwischen Ägypten und dem subsaharischen Afrika auf. Gerade Khartum war einer jener Orte, an denen sich Routen, Märkte, Einflussbereiche und Kulturen trafen und überlagerten. ${ }^{52}$

Von El Obeid, der Hauptstadt der im Südwesten des ägyptischen Einflussbereichs liegenden Provinz Kordofan, begab sich Russegger mit einem 450 Personen starken Expeditionsheer zu den Nuba-Bergen. ${ }^{53}$ Das Gebiet war bereits Jahrhunderte vor der

Russegger, Reisen, Bd. 2/2, S. 574

Russegger, Reisen, Bd. 2/1, S. 43-44.

Russegger, Reisen, Bd. 2/2, S. 71.

48 Christof Hamann/Alexander Honold, Der Kilimandscharo, in: Jürgen Zimmerer (Hrsg.), Kein Platz an der Sonne. Erinnerungsorte der deutschen Kolonialgeschichte, Frankfurt a. M. 2013, S. 81-95, hier S. 82.

49 Russegger, Reisen, Bd. 1/1, S. 15.

50 Fischer, Österreich im Nahen Osten, S. 73.

51 Russegger, Reisen, Bd. 2/1, S. 515-516.

52 Felicitas Becker, Netzwerke vs. Gesamtgesellschaft: ein Gegensatz? Anregungen für Verflechtungsgeschichte, in: Geschichte und Gesellschaft 30 (2004), Heft 2, S. 314-324, hier S. 319.

53 Gritsch, Die Beziehungen Österreich-Ungarns zum ägyptischen Sudan, S. 295. 
Eroberung zwischen den Sultanaten Sannar und Darfur umstritten. Aufgrund der lockeren Bindung an die Zentralregierung setzten sich auch nach der Eroberung Kämpfe zwischen verschiedenen Gruppen fort, die sich nicht zuletzt an den Rechten der Goldschürfung entzündeten. ${ }^{54}$ Die als Nuba bezeichneten Gruppen befanden sich in ständigen Konflikten mit dem Sultanat Taqali, welches sich den Eroberungsfeldzügen des Vizekönigs erfolgreich widersetzen konnte..$^{55}$ Auch Pallme gab an, Zeuge dieser kriegerischen Auseinandersetzungen geworden zu sein. ${ }^{56}$ Russegger behauptete sogar, dass der Sultan von Taqali „sich eine gewisse Territorialherrschaft über den Golddistrikt südlich von Scheibun angemasst" habe, weshalb er als potentieller Kollaborateur für österreichische Händler interessant wurde. ${ }^{57}$ Diese bildeten im ägyptisch-sudanesischen Raum ein informelles Netzwerk, das vor allem außerhalb der Staatsgrenzen operierte. Dennoch waren die Interessen der Habsburgermonarchie im Hintergrund präsent, da das Gold schließlich in den Hafen von Triest einlaufen und von dort weiter nach Wien transportiert werden sollte.

In den wasserreichen Gebirgszügen Taqalis und Nubas fand Russegger reiche Goldvorkommen. Während größere Stücke „an ihre Häuptlinge abzuliefern“ seien, werde der gewonnene Goldstaub "geschmolzen und in Ringe von verschiedener Grösse [...] gegossen"58. Von Pallme, der entlang des Weißen Nils ins südliche Kordofan vordrang, wurden die Territorien der Dinka und Schilluk südlich des Taqali-Gebirges als potentielle Golddistrikte angesehen. ${ }^{59}$

Im Oktober 1837 folgte Russegger dem Blauen Nil nach Süden. Der Herrscher von Roserres, Melek Soliman, begleitete das Expeditionsteam nach Fassokl. Russegger konnte ihm kaum hilfreiche Informationen bezüglich der Goldvorkommen abringen, "denn stets, wenn ich auf diesen Gegenstand kam, wusste er durch eine geschickte Wendung zu parieren, oder sagte geradezu, er verstehe mich nicht"60. Der Grund für diese Zurückhaltung von Informationen wird kaum in der von Pallme geäußerten Vermutung gelegen haben, dass „diese blöden Menschen den Werth desselben [des Goldes] nicht zu schätzen" wissen ${ }^{61}$, sondern vielmehr auf der Überlegung gegründet haben, sich selbst die reichsten Gebiete zu sichern. ${ }^{62}$

Zwar sei „die Methode des Goldausziehens, so wie die Neger [Nuba] sie handhaben, sehr langsam und zeitraubend“, doch „kann nicht geläugnet werden, dass sie aber auch

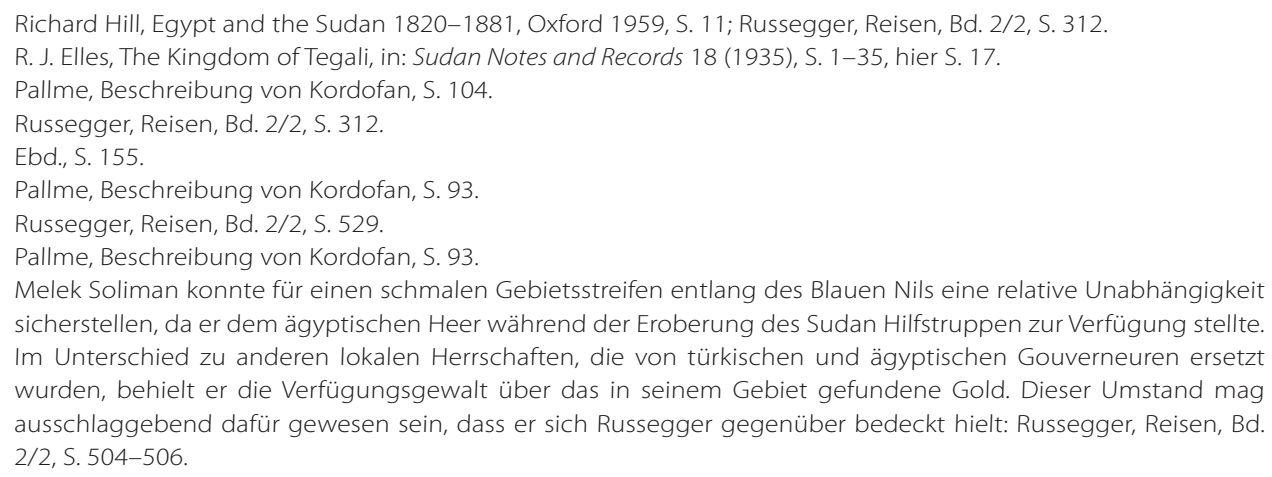
sicherstellen, da er dem ägyptischen Heer während der Eroberung des Sudan Hilfstruppen zur Verfügung stellte. Im Unterschied zu anderen lokalen Herrschaften, die von türkischen und ägyptischen Gouverneuren ersetzt wurden, behielt er die Verfügungsgewalt über das in seinem Gebiet gefundene Gold. Dieser Umstand mag ausschlaggebend dafür gewesen sein, dass er sich Russegger gegenüber bedeckt hielt: Russegger, Reisen, Bd. 2/2, S. 504-506. 
damit so richtige Resultate [...] erzielen, wie wir mit unsern besten Sichertrögen"63. Die Goldgräber*innen von Fassokl versetzten das Wasser durch eine Schale in eine kreisende Bewegung, damit sich „das Gold im Centro des Rotationskreises ansammelt und der taube Schlich am Rande desselben mit den Fingern abgestrichen werden kann"64. Eine Person könne an einem achtstündigen Arbeitstag allerdings höchstens zweihundert Pfund ${ }^{65}$ des goldführenden Alluviums waschen. Bei einer gut gewählten Stelle enthalte das Alluvium einen Goldanteil von 0,5-1 Prozent, was einen Maximalwert von 0,01 Loth ${ }^{66}$ Gold und damit dem Wert von 13 Kreuzern entspreche. „Würde jedoch auch nur die allereinfachste, europäische Aufbereitungs-Methode eingeführt, so würde es natürlich nicht schwer halten, wenigstens ein zehnfaches Aufbringen zu erreichen." ${ }^{167}$ Hierin zeigt sich der von Profitabilitätsdenken gelenkte Blick auf die als primitiv erachteten lokalen Goldschürfungsmethoden. Russegger sah in den Goldgebieten am Fasangoru die profitabelste und aufgrund der nahegelegenen Holzvorkommen strategisch günstigste Stelle für die Goldschürfung. Auch die Schiffbarkeit des Weißen Nils an dieser Stelle sei ein wichtiger Faktor. Durch den geplanten Bau einer Schienenbahn für Pferde und einer Förderhütte wäre die Infrastruktur für die Schürfung und den Transport des Goldes gegeben. Er erwog beginnende Schürfarbeiten "mit ungefähr fünfhundert Mann, Eingebornen und Soldaten“, wofür aber die „Rätterwäsche, Senngitter-Pochwerke mit Amalgamation am Satze“ als die am sinnvollsten eingeschätzte Verfahrensweise angesehen wurde. ${ }^{68}$ Den Transfer von Aufbereitungsmaschinen und Know-how aus Europa hielt er für unumgänglich, da er

„einsah, dass alle unsere Entdeckungen in spe der egyptischen Verwaltung nichts nützen wenn sie nicht brauchbare Leute hätte, die im Stande wären die Bergbau- und Hütten-Manipulationen nach technischen Regeln [...] und Prinzipien einer verständigen durchdachten Wirthschaft zu leiten." ${ }^{169}$

Deshalb schlug er vor, "zehn seiner fähigsten Eleven aus der polytechnischen Schule zu Kairo auszuwählen und der Expedition zuzutheilen“ und „die fähigsten unter ihnen zur weitern Ausbildung [...] nach Österreich zu senden [...] und sie dann zu ihrer technischen Ausbildung an die polytechnische Schule zu Wien und auf die Bergschule zu Schemnitz zu senden" $"$.

Die Gebiete um den Berg Dschebel Tul bei den Schongollo beschrieb Russegger als "ein wahres Eldorado"71. Ignaz Pallme wollte festgehalten wissen, dass "kein anderes Metall als Gold und Silber an den Weibern" zu sehen gewesen sei - laut seinen Berichten hätten „sogar viele Sklavinnen [...] Gold an sich“ getragen. ${ }^{72}$ Russeggers Expedition

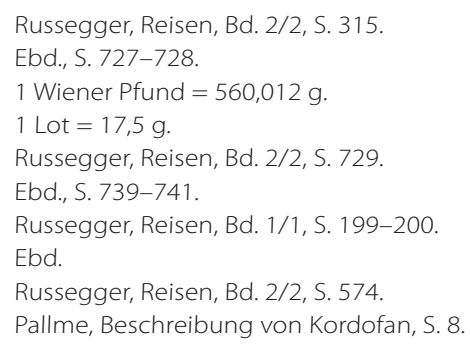


wurde nun auch von Mustafa-Bey, dem Militärkommandanten des Sudan, und seinem 1.200 Personen starken Begleitheer flankiert. Dessen Ziel war es, die umstrittenen Gebiete unter die ägyptische Zentralgewalt zu bringen und sich auch persönlich am Gold zu bereichern. ${ }^{73}$ Nachdem Mustafa-Bey ganze Dörfer der Schilluk in Brand setzen ließ, folgte eine Reihe von Gegenangriffen, ${ }^{74}$ wodurch sich Russegger und sein Team zum Rückzug gezwungen sahen. ${ }^{75}$ Die breite Schilderung dieser Kämpfe lässt vermuten, dass Russegger die im Süden von Fassokl ausgefochtenen Konflikte als wesentliches Hindernis für ein weiteres Vordringen goldsuchender Händler betrachtete. Gleichzeitig äußerte er die Überzeugung, dass für künftige Expeditionen das Hauptquartier nicht in Khartum, sondern viel weiter südlich, „in Fassokl, in Scheibun oder am Tira", den Endpunkten seiner Reise, aufzuschlagen sei. Fassokl eigne sich besser für Erkundungen, ob es weiter südlich noch unerschlossene Goldquellen gab. ${ }^{76}$

Insbesondere diese Gebiete im südlichen Sudan, in denen bis weit in die zweite Hälfte des 19. Jahrhunderts hinein prämonetäre Zahlungsformen üblich waren, versprachen europäischen Händlern große Gewinne. Russegger wies in seinen Reiseberichten darauf hin, dass europäische Händler durch Tauschhandel ${ }^{77}$ viel Gold erwerben könnten, wenn sie "den Mangel eines geregelten Gewichtssystems sehr geschickt für sich zu benützen verstünde[n]"

Als Russegger mit seinem dezimierten Expeditionsteam am 27. Juli 1838 in Alexandria ankam und dem Vizekönig die Ergebnisse darlegte, sprach Muhammad Ali von seiner Absicht, selbst nach Fassokl reisen zu wollen. Er veranschlagte dafür eine Reisedauer von zwanzig Tagen und teilte Russegger seinen Plan mit, die Katarakte zu zertrümmern, „um die Goldgruben mit zehntausend Mann in Arbeit nehmen zu können"79. Muhammad Alis „Zehntausendmann-Theorie" basierte auf folgender Annahme: Wenn ein Mann pro Tag einen Taler Gold schürfen könnte, müssten „10.000 Mann offenbar des Tages für 10.000 Thaler erzeugen"80. Damit schätzte der Vizekönig die Menge des Goldes viel zu hoch ein und schien überdies die Augen vor dem Umstand zu verschließen, dass eine solche Förderung nur schrittweise aufgebaut werden könne. Russegger sah in dieser "Goldmanie" ${ }^{\prime \prime 1}$, die alle wissenschaftlichen Ergebnisse der Expedition ignorierte, „einen tiefern Grund" als den „Mangel an technischer Kenntnis", nämlich jenen, "dass Mehemed-Ali ernstlich damals in dem exzentrischen Betriebe der Goldwäschen sein Heil suchte" 182 - und dies in einer Zeit, als in Alexandria die Pest ausbrach, als der niedrige Wasserstand des Nils ein Hungerjahr ankündigte und als nach osmanischen

73 Gritsch, Die Beziehungen Österreich-Ungarns zum ägyptischen Sudan, S. 297; Peter Malcom Holt (Hrsg.), The Sudan of the Three Niles. The Funj Chronicle 910-1288/1504-1871 (Islamic history and civilization. Studies and Texts 26), Leiden-Boston-Köln 1999, S. 109; Russegger, Reisen, Bd. 2/2, S. 195. Russegger, Reisen, Bd. 2/2, S. 585-587.

75 Ebd., S. 610.

76 Ebd., S. 11

77 Ebd., S. 537. „Mit Waffen und Bijouteriewaaren könnte man [...] im Tausche gegen Gold einträgliche Geschäfte machen."

78 Ebd., S. 313

79 Russegger, Reisen, Bd. 2/3, S. 101-102.

80 Ebd., S. 108.

81 Ebd., S. 115.

82 Ebd. 
Angriffen auf Ägypten die europäische Anerkennung der Unabhängigkeit Ägyptens ausblieb. Den Plan des Vizekönigs beurteilte Russegger also als einen Akt der Verzweiflung, als Flucht vor der politischen Realität, weshalb er sich zur Auflösung der Expedition gezwungen sah.

Der thüringische Reisende Alfred Brehm berichtete davon, dass er im Juni 1850 Hassan-Effendi, einen der im Zuge der Russegger-Expedition zur Ausbildung nach Wien geschickten Zöglinge, in Karthum antraf. Zusammen mit drei seiner Studienkollegen, die der deutschen Sprache mächtig waren, leitete Hassan-Effendi die Goldwäschereien in Fassokl, um die es Brehm zufolge „ziemlich trübe“ bestellt war. ${ }^{83}$ Auch Martin Ludwig Hansal begegnete diesem im September 1855 und berichtete davon, dass die Schürfbetriebe in Fassokl „,vor einem Jahre als nicht rentabel aufgegeben worden“" seien. ${ }^{84}$

\subsection{Baumwolle, Elfenbein und Gummi. Der Sudan als Lieferant günstiger Rohstoffe}

\subsubsection{Baumwolle: Wirtschaftsmotor für österreichisch-ägyptische Beziehungen?}

Als Muhammad Ali 1817 den französischen Textilfabrikanten Louis Alexis Jumel (1785-1823) nach Kairo kommen ließ, war dies der Startschuss für den Anbau der langfaserigen und hochqualitativen ägyptischen Baumwolle im gesamten Land. Die JumelBaumwolle schien das Potential zu besitzen, die amerikanische Sea Island-Baumwolle abzulösen. ${ }^{85}$ Prokesch und Russegger zufolge war der Boden in der Nähe des Nils, insbesondere im tropischen Südsudan, optimal für die Anpflanzung der Baumwolle geeignet. ${ }^{86}$ Zudem erleichtere die Nähe zum Nil die Bewässerung, die mithilfe von Sakien, von Ochsen oder von Eseln angetriebenen Schöpfrädern, durchgeführt wurde. ${ }^{87}$ Prokesch berichtete davon, dass florentinische Baumwollfabrikanten ins Land geholt wurden und dass das Personal fast ausschließlich aus europäischen Arbeitskräften bestand. ${ }^{88}$ Um Kosten zu vermindern, müsse er "sich nach und nach der kostspieligen Hülfe der Europäer entschlage[n]"89 und das Arbeitspersonal aus der ansässigen Bevölkerung rekrutieren.

Prokesch führte zahlreiche Details zu Anbau, Ernte, Transport und Vermarktung von Baumwolle an. Eine Staude könne über fünfzig Jahre alt werden, es sei aber am profitabelsten, alle drei Jahre eine Neupflanzung vorzunehmen. ${ }^{90}$ Die Ernte finde zwischen Juli und Dezember statt, ${ }^{11}$ eine gute Staude könne pro Jahr 1,1 Kilogramm Baumwolle abgeben. ${ }^{92}$ Täglich könne eine Person acht bis zehn Kilogramm Baumwolle ernten, eine etwas geringere Menge könne täglich durch die Doppelwalze, die die Baumwolle

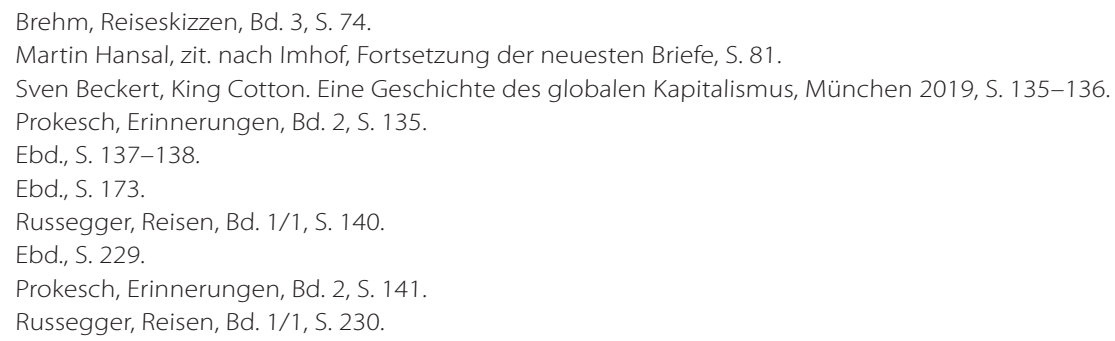


aus der Hülle löst, gereinigt werden, wobei Kinder und Frauen helfen würden. Die gereinigte Baumwolle werde dann in die Magazine der Regierung, die es in jeder der 24 Provinzgouvernementsstädte gab, geliefert, wo sie zur Erleichterung des Transports durch englische Pressen zu Ballen verarbeitet werden. ${ }^{93}$ Die Baumwolle gelange schließlich nach Kairo, wo sie in den größeren Spinnereien weiterverarbeitet werde oder nach Alexandria, wo sie auf Schiffe geladen und nach Europa ausgeführt werde. Muhammad Ali erwog im Juli 1838 sogar, den Baumwollexport ausschließlich über Triest abzuwickeln. ${ }^{94}$ Bereits 1829 hatten die Ausschüsse der niederösterreichischen Baumwollindustrie von der Wiener Regierung gefordert, die Handelsverbindungen mit Ägypten zu intensivieren, um die steigende Nachfrage immer breiterer Gesellschaftsschichten nach Baumwollkleidern zu befriedigen. ${ }^{95}$

Die ufernahen Gebiete des Weißen Nils wurden als geeignetes Anbaugebiet angesehen, ${ }^{96}$ weil einerseits die Möglichkeit der Bewässerung bestand, und die Stauden andererseits von Überschwemmungen geschützt waren. ${ }^{97}$ Da Baumwolle niemals längerer Feuchtigkeit ausgesetzt sein darf, mussten Produkte, wie etwa das sudanesische Grundnahrungsmittel der Dura-Hirse, für deren Gedeih die Überschwemmung unabdingbar war, "leiden“. Deshalb erwog Prokesch den monokulturellen Anbau von Baumwolle in Gegenden, die zwar in der Nähe des Ufers, aber nicht direkt im Schwemmland lagen. ${ }^{98}$ Dazu kämen auch Gebiete am Blauen Nil infrage, wo sich die Bewässerung allerdings schwieriger gestalte, da die Ufer höher liegen. ${ }^{99}$ Auch in Gondar und den umliegenden Gebieten des äthiopischen Hochlandes gab es bedeutende Baumwollfelder und -fabriken. ${ }^{100}$

Der wesentliche Grund, warum der Anbau nicht intensiviert wurde, lag laut Pallme nicht darin, dass die Bevölkerung das Potential der Baumwolle nicht kannte, sondern vielmehr daran, dass „es doch bekannt sey, daß man ihnen von der gewonnenen Baumwolle wenig oder gar nichts lassen würde"101. Aufgrund des ägyptischen Monopols über die Rohstoffe im Sudan war der Handel mit europäischen Kaufleuten für sudanesische Landbesitzende deshalb anfangs durchaus attraktiv. ${ }^{102}$ Russegger wies darauf hin, dass es auch zahlreiche Spinnereien in Oberägypten gab. Für Händler dürfte diese Information von Interesse gewesen sein, da mit der Verarbeitung der Baumwolle in diesen Fabriken die hohen Transport- und Zollkosten begrenzt hätten werden können. ${ }^{103}$

\footnotetext{
93 Prokesch, Erinnerungen, Bd. 2, S. 141-143.

94 Fischer, Österreich im Nahen Osten, S. 94-95.

95 Johann Slokar, Geschichte der österreichischen Industrie und ihrer Förderung unter Kaiser Franz I. Mit besonderer Berücksichtigung der Großindustrie und unter Benützung archivalischer Quellen, Wien 1914, S. 215.

96 Russegger, Reisen, Bd. 2/2, S. 16-17.

97 Prokesch, Erinnerungen, Bd. 2, S. 135.

98 Ebd., S. 144.

99 Russegger, Reisen, Bd. 2/2, S. 16, 466.

100 Heuglin, Reisen in Nord-Ost-Afrika, S. 52.

101 Pallme, Beschreibung von Kordofan, S. 135-136.

102 Roger Owen, Egypt and Europe. From French expedition to British occupation, in: Roger Owen/Bob Sutcliffe (Hrsg.), Studies in the theory of imperialism, London 1972, S. 195-209, hier S. 200-201.

103 Russegger, Reisen, Bd. 2/1, S. 384.
} 
Für das Färben der Textilien kamen Disteln, Hennasträucher sowie Indigopflanzen in Betracht. ${ }^{104}$ In Abu Tig, Tahta, Assiut, Mellaoui und Manfalut gab es bereits Indigofabriken. ${ }^{105}$ Als Hansal das Land 1855 bereiste, fand er die am Blauen Nil liegende Indigofabrik von Kamlin, die ein Unternehmer aus Württemberg namens Bauer bis zu seinem Tod leitete, bereits im Verfall. ${ }^{106}$ Ein ähnliches Schicksal ereilte die Baumwollindustrie. Sven Beckert sieht den Hauptgrund für den Niedergang der ägyptischen Baumwollfabrikation in den 1850er-Jahren darin, dass Ägypten den Übergang vom Kriegskapitalismus zum Industriekapitalismus nicht schaffte. Anders als Großbritannien, das dem Land des Vizekönigs den Rang ablief. ${ }^{107}$

\subsubsection{Eisen: Europäische Maschinen für die sudanesische Industrie?}

Im Norden Kordofans fand Russegger enorme Vorkommen Raseneisenstein und eine einfache Eisenindustrie vor. Den Abbau kritisierte er als "roh" und "unwirtschaftlich": Die Bergleute schlugen schlugen unzählige, kaum ein Meter nebeneinanderliegende, runde Tagschächte von maximal 1,5 Metern Durchmesser und drei Metern Tiefe. Es wurde nicht tiefer gegraben, da das Verständnis fehlte, die Schächte vor dem Einsturz zu bewahren. Dadurch könne nur die oberste Schicht abgebaut werden, die unteren Schichten des wechsellagernden Terrains, meistens noch eisenhaltiger, blieben ungenutzt. Auch der Schmelzprozess sei sehr dürftig. Die Bergleute hoben kegelförmige Gruben aus dem Sandboden aus, legten das eisenhaltige Erz sowie Holzkohlen hinein und zündeten das Gemenge an. Mithilfe eines Blasbalgs wurde der Schmelzprozess beschleunigt, bis nach circa zehn Stunden der größte Teil geschmolzen war. Nachdem die Masse ausgekühlt war, wurden die festen Erze für den zweiten Schmelzgang beiseite gelegt, während die Schlacke von der oberen, unbrauchbaren Schicht gesondert wurde. Der untere, poröse Teil und die festen Erze aus dem ersten Schmelzgang wurden ein zweites Mal geschmolzen. Als Resultat blieb schließlich der Eisenkönig, der von den Schmieden als weiches Eisen verarbeitet wurde. ${ }^{108}$ Der doppelte Schmelzprozess beanspruchte zehn bis 14 Stunden Zeit, in denen acht bis elf Kilogramm Eisen gewonnen werden konnten. ${ }^{109}$ Ein Zentner ${ }^{110}$ unverarbeiteten Eisens kostete Russegger zufolge 13-15 Taler, „weit unter der Mühe, dem Material- und Zeitaufwand, der den armen Schwarzen bei ihrer Eisenfabrikation zugeht ${ }^{\prime 111}$. Zwar sei das Eisen „von ausnehmender Güte", doch könne durch verbesserten Abbau und Schmelze viel mehr Eisen gewonnen werden. ${ }^{112}$

\footnotetext{
104 Russegger, Reisen, Bd. 1/1, S. 291-292.

105 Russegger, Reisen, Bd. 2/1, S. 384.

106 Imhof, Fortsetzung der neuesten Briefe, S. 97-98.

107 Beckert, King Cotton, S. 167-168.

108 Russegger, Reisen, Bd. 2/2, S. 289-292.

109 Ebd., S. 294.

1101 Zentner $=56,1288 \mathrm{~kg}$.

111 Russegger, Reisen, Bd. 2/2, S. 293-294.

112 Ebd.
} 
Ein weiteres Problem sah Russegger in der Beschaffung von Brennmaterial. Meistens wurde Kohle aus Mimosensträuchern gebrannt. ${ }^{13}$ An anderer Stelle sprach Russegger von möglichen Naphtha-, Schwarz- und Braunkohlevorkommen in den Kalkzügen von Darfur, einer Provinz westlich von Kordofan, die sich mit Ägypten im Krieg befand. Durch diese fossilen Energieträger, die einen viel höheren Brennwert haben als die Kohle der Mimosen, hätte der Schmelzprozess wesentlich beschleunigt werden können. ${ }^{114}$

1828/29 hatte Muhammad Ali vier Engländer aus den Eisenfabriken in Kairo nach Bara in Nordkordofan ausgesandt, um die dortige Eisenindustrie zu modernisieren. Allerdings wurden drei von ihnen schon bald Opfer der schweren klimatischen Bedingungen, der vierte kehrte nach Kairo zurück. Ein in London verfertigter Flammofen lag als Zeuge der gescheiterten Modernisierungsmission noch 1837 ungebraucht in einem Magazin in Bara. ${ }^{115}$ Während Alfred Brehm 1848 "gänzliche[n] Mangel an Ausbildung" diagnostizieren und nur "erbärmliche Werkzeuge" sehen wollte, ${ }^{116}$ stellte Heuglin 1863 für die Eisenindustrie eines viel weiter südlich liegenden Gebietes, jenem der Djur und Dor, die an den westlich des Weißen Nils liegenden Zuflüssen Bahr al-Ghazāl und Jur ansässig waren, einen fortgeschrittenen Zustand fest. Von deren Essen, Schmelzöfen und Frischfeuern fertigte er Zeichnungen an. ${ }^{17}$

\subsubsection{Gummi: Schwierigkeit des Transports eines vielversprechenden Rohstoffes}

Weite Mimosenwälder erstrecken sich über die Landschaften des heutigen Sudan und Südsudan. Insbesondere im Territorium der Nuba in Südkordofan fanden die Reisenden ausgedehnte Wälder dieser Pflanzen, ${ }^{118}$ die in der jährlichen Regenzeit einen Wundsaft - Gummi - aussondern, welcher von Heuglin als das „beträchtlichste Handelsprodukt Kordofans" bezeichnet wurde. ${ }^{119}$ Das Gummi wird immer nach der Regenzeit, von Dezember bis Februar, eingesammelt ${ }^{120}$ und anschließend in geflochtene Körbe gegeben, die wiederum in Bastsäcke gepackt werden. Für den Transport kamen Kamele infrage, die ungefähr vierzig solcher Körbchen à fünf Kilogramm, also ein Gesamtgewicht von zweihundert Kilogramm, tragen konnten. ${ }^{121}$ Wegen der mangelhaften Verpackung ging allerdings häufig ein beträchtlicher Teil des Gummis auf dem Transportweg verloren. Hitze und Wind taten ein Übriges, sodass das Gummi eintrocknete. Auch Brehm berichtete, dass jede Ladung ungefähr zwölf Prozent an Gewicht verlor. ${ }^{122}$ Die Regierung ließ das Gummi von den Kabobisch in Karawanen von Nordkordofan

\footnotetext{
113 Russegger, Reisen, Bd. 2/2, S. 293.

114 Russegger, Reisen, Bd. 2/1, S. 355.

115 Russegger, Reisen, Bd. 2/2, S. 238.

116 Brehm, Reiseskizzen, Bd. 1, S. 209.

117 Heuglin, Reise in das Gebiet des Weissen Nil, S. 196-199.

118 Pallme, Beschreibung von Kordofan, S. 25.

119 Heuglin verglich die dortige Eisenproduktion mit einer katalanischen Schmiede mit tönernem Essen und Schmelzöfen: Heuglin, Reise in das Gebiet des Weissen Nil, S. 37.

120 Pallme, Beschreibung von Kordofan, S. 138.

121 Ebd., S. 173.

122 Brehm, Reiseskizzen, Bd. 1, S. 201.
} 
nach Dongola bringen, ${ }^{123}$ wofür zwanzig Tage veranschlagt wurden. ${ }^{124}$ Da das Gummi dem staatlichen Monopol unterlag, konnte die Regierung auch den Preis diktieren. Pallmes Bericht zufolge mussten die Scheichs der Kabobisch für das beim Transport verloren gegangene Gummi aufkommen - und zwar nicht zum Einkaufspreis, den die Regierung in Dongola entrichtete, sondern zum Verkaufspreis der Waren in Alexandria inklusive Transport- und Zollgebühren. Darüber hinaus erhielten die Kabobisch nur ein Viertel bar ausgezahlt, den Rest tauschte die Regierung gegen Naturalien ein, sodass ihnen kaum ein Gewinn blieb. ${ }^{125}$ Von Dongola gingen die Karawanen weiter nach Wadi Halfa, wo das Gummi auf Nilbarken geladen und nach Kairo oder Alexandria transportiert wurde. Der Kauf und Transport von zweihundert Kilogramm Gummi von Nordkordofan nach Kairo kostete insgesamt 25 Taler. $^{126}$

Bara war laut Pallme der geeignete Platz für den Einkauf. Er regte an, das Gummi in Ochsenhäute zu packen, um den wertvollen Rohstoff besser vor klimatischen Einflüssen zu schützen. Zudem wies er darauf hin, dass in den Wäldern große Mengen Gummi verfaulten, denn „Mehemed Ali benutzt es nicht, will aber auch nicht, daß es durch andere benutzt werde"127. Deshalb erwog Pallme dort einen Einkauf durch Tauschhandel. ${ }^{128}$ Russegger ging davon aus, dass der Handel mit dem gefragten Gummi intensiviert werden könne, „würde man den Eingebornen den Centner zu 30 Piaster vergüten, ${ }^{129 "}$ nicht zu den üblichen zwölf bis 15 Piastern. Er war überzeugt, dass die Jahresproduktion dadurch von 840 auf 1.680 Tonnen verdoppelt werden könne. ${ }^{130}$ In Ägypten und im Sudan war das Konzept der Lohnarbeit neu, weshalb große Teile der Gesellschaft noch nicht mit dem sich in Europa durchsetzenden Credo vertraut waren, dass mit der Steigerung der Löhne auch die Produktivität gefördert werden könne.

Brehm berichtete davon, dass 1851 eine Art Inflation im Gummihandel des Sudan eintrat. Europäische Kaufleute hätten, als das Monopol der Regierung unter Muhammad Alis Enkel und Nachfolger Abbas I. Pascha (1813-1854) aufgehoben wurde, ${ }^{131}$ zahlreiche industriell gefertigte Baumwollprodukte aus Europa ins Land gebracht, um diese gegen das begehrte Gummi einzutauschen. Da der Bedarf an Baumwollkleidern bald gedeckt war, fiel deren Preis um zwanzig Prozent, wohingegen der Preis für einen Zentner Gummi von 15 auf hundert Piaster stieg. ${ }^{132}$

\subsubsection{Elfenbein: Handel mit einem Prestigeobjekt aus den Kolonien}

Exotische Produkte wie Elfenbein waren in Europa seit jeher begehrt, weil deren Besitz

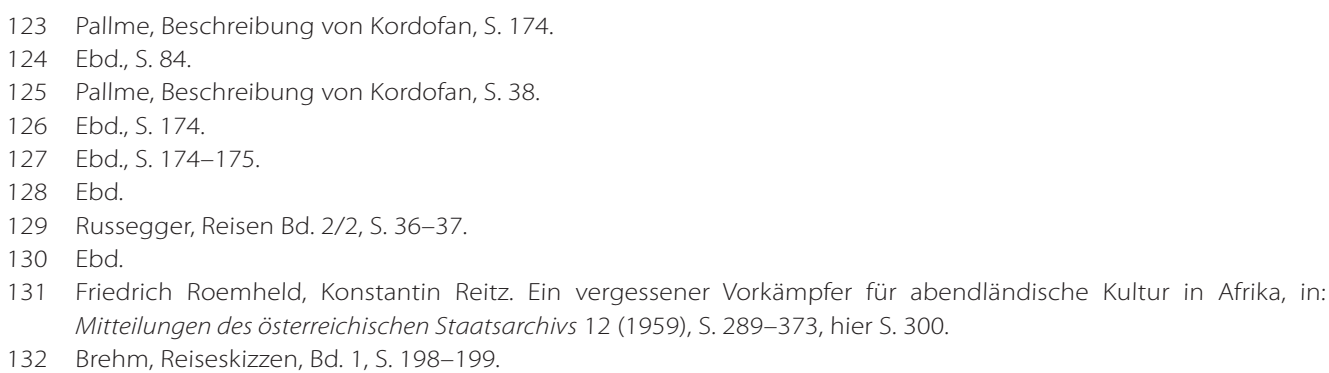


soziales Kapital sichtbar machen konnte. ${ }^{133}$ Gleichzeitig markierte der Besitz von Waren wie Elfenbein, Straußenfedern und Tierfellen die Macht des (europäischen) Menschen über die Natur und nicht zuletzt über die oftmals als „animalisch“ gezeichneten Völker Afrikas. Europäische Händler konnten mit Elfenbein beträchtliche Gewinne erzielen. Es konnte sowohl von den Zähnen des Nilpferds wie von den Stoßzähnen von Elefanten gewonnen werden. Während die Nilpferdjagd überall entlang des Nils betrieben wurde, ${ }^{134}$ waren die Elefanten weiter südlich damals noch im gesamten subsaharischen Raum heimisch. Besonders große Herden fand Pallme im Siedlungsgebiet der Schilluk, zu beiden Ufern des Weißen Nils. ${ }^{135}$

Obwohl der Elfenbeinhandel unter Muhammad Ali monopolisiert wurde, fanden einige sudanesische Händler Schlupflöcher, um Bestimmungen zu umgehen, sodass große Mengen an Elfenbein ihren Weg zu den Hafenstädten am Roten Meer fanden. Die dort tätigen englischen Händler zahlten „gut und prompt, wogegen für Mehemed Ali nur das übrig bleibt, was [...] nicht bis Suakem [Suakin] kommt ${ }^{136 . " ~ I n d i s c h e ~ A g e n t e n ~}$ erwarben das Elfenbein und luden es unter Geheimhaltung auf größere Handelsschiffe, die es nach Indien brachten. ${ }^{137}$

Pallmes ausführlicher Bericht über die massive britische Konkurrenz an der Küste des Roten Meeres ließ die Frage nach möglichen Alternativen für österreichische Händler aufkommen. Sinnvoll sei es, in Absprache mit den türkischen Offizieren im Sudan, die sich schon mit Wein und Branntwein gewinnen ließen, Einkauf und Transport des Elfenbeins zu organisieren. Das Elfenbein könne in den größeren Städten Darfur, alFaschir und Kobbei, erworben werden - auch im Tausch gegen europäische Produkte. ${ }^{138}$ Bei den Angaben zum Einkaufspreis lassen sich auffällige Unterschiede erkennen. Während Pallme diesen für das Jahr 1838 in al-Faschir und Kobbei mit 15 Talern je „Cantar zu 112 Rottoli (88 Wiener Pfund)" angab,"139 betrug der Einkaufspreis 1850 für einen „arabischen Zentner" des qualitativ hochwertigsten Elfenbeins laut Brehm in El Obeid 110, in Khartum 120 und in Kairo 180 Taler. ${ }^{140}$ Einerseits kann diese signifikante Abweichung daran liegen, dass der "Cantar" und der "arabische Zentner" nicht ein und dasselbe Gewichtsmaß waren und je nach Region unterschiedlich umgerechnet, von den Reisenden jedoch als identisch wahrgenommen wurden. Möglicherweise gibt es aber noch einen anderen Grund: Wird den Berichten Brehms ${ }^{141}$ und Heuglins Glauben geschenkt, so wurden im Laufe der 1840er-Jahre mehrere, dem Lauf des Weißen Nils

133 Bereits im Mittelalter war Elfenbein ein begehrtes Material für sakrale Gegenstände (z. B. Kruzifixe, Reliquiare, Buchdeckel etc.). Mit der Intensivierung des Indien- und Afrikahandels durch Handelskompanien im 18. Jahrhundert gelangten größere Mengen Elfenbeins nach Europa, wodurch es auch in wohlhabenden Kreisen des Bürgertums Verwendung fand, z. B. für Klaviertasten und Besteckgriffe: Wendt, Vom Kolonialismus zur Globalisierung, S. 199.

134 Russegger, Reisen, Bd. 2/1, S. 512.

135 Pallme, Beschreibung von Kordofan, S. 92-93.

136 Ebd., S. 176.

137 Ebd.

138 Ebd., S. 177-178.

139 Ebd., S. 175.

140 Brehm, Reiseskizzen, Bd. 1, S. 200.

141 Brehm, Reiseskizzen, Bd. 3, S. 98. 
sowie seiner Zuflüsse Bahr al-Ghazāl und Jur nach Süden folgende Handelsexpeditionen unternommen. Die europäischen Händler erwarben große Mengen Elfenbein im Tausch gegen venezianische und böhmische Glasperlen, „welche das Land überschwemmten", und deren Wert folglich stark sank. ${ }^{142}$ Die lokale Bevölkerung hatte Elfenbein im Überfluss und benutzte es laut Heuglin sogar als „Pflöcke zum Anbinden der Kühe"143, doch bald erkannte sie, "dass das Elfenbein viel mehr werth sein muss, als elende, zerbrechliche Glaswaaren, die bereits Jedermann besitzt" ${ }^{\prime 144}$. Wahrscheinlich stehen die Abweichungen zwischen den Angaben Pallmes und Brehms mit diesen Entwicklungen in Zusammenhang.

Die von Heuglin beschriebene Intensivierung des Handels entlang des Weißen Nils und seiner Zuflüsse trug nach dem Tod Muhammad Alis dazu bei, dass 1851 der Elfenbeinhandel am Weißen Nil dem staatlichen Monopol entzogen und legalisiert wurde. Es wurden mehrere Zeraib, kleinere Handelsniederlassungen, gegründet, und das Gebiet von europäischen und türkischen Händlern durchdrungen. Heuglin berichtete davon, dass jeder Zeribah-Besitzer "das Land und Volk, bei dem er sich etablirt hat, als sein Eigenthum" behandelte. ${ }^{145}$

\subsection{Glasperlen, Alkohol und Schwerter. Der Sudan als Absatzmarkt für österreichische Produkte}

Mit dem sprunghaften Anstieg industrieller Produktion in Österreich stieg auch der Bedarf an günstigen Rohstoffen, die die Reisenden im Sudan zu finden glaubten. Umgekehrt bestand Hoffnung darauf, diesen Teil Afrikas als Absatzmarkt für Waren aus der heimischen Industrie zu gewinnen. Import und Export hingen eng miteinander zusammen, zumal die Praxis des Tauschhandels weit verbreitet war.

Für den Weinanbau war der Sudan wegen seines tropischen Klimas kaum geeignet, weshalb Wein importiert werden musste. ${ }^{146}$ Aber auch dieser war in den meisten Fällen ungenießbar, da er während des Transports aufgrund der klimatischen Schwankungen Schaden nahm. Dennoch konsumierte die lokale Bevölkerung gern auch den „schlechten, sauern Wein"147. Besser eignete sich Schnaps, der sehr geschätzt wurde, weil seine Lagerung einfacher war. Zudem könne „in den heißen Ländern den mäßigen Genuß geistiger Getränke aus gesundheitlichen Rücksichten [...]" nicht entbehrt werden. ${ }^{148}$ Das Alkoholverbot im Islam sei keineswegs ein Hindernis für den Handel mit Alkoholika: „Alle diese Mohammedsanbeter scheinen es mit dem Koran nicht so strenge zu nehmen, denn der Genuß geistiger Getränke [...] ist unter ihnen so gewöhnlich, als ob es kein Verbot wäre."149 Brehm berichtete davon, dass in dem am Blauen Nil liegen-

\footnotetext{
142 Heuglin, Reise in das Gebiet des Weissen Nil, S. 11-13.

143 Ebd., S. 13.

144 Ebd., S. 166.

145 Ebd., S. 167

146 Brehm, Reiseskizzen, Bd. 1, S. 199

147 Martin Hansal, zit. nach Imhof, Fortsetzung der neuesten Briefe, S. 67.

148 Brehm, Reiseskizzen, Bd. 1, S. 199.

149 Martin Hansal, zit. nach Imhof, Fortsetzung der neuesten Briefe, S. 46.
} 
den Kamlin, zwei Tagesreisen südlich von Khartum, eine Branntweinbrennerei errichtet wurde. Der Schnaps wurde aus Datteln aus Dongola gebrannt. ${ }^{150}$

Das nahezu im gesamten Sudan wachsende Zuckerrohr diente als Basis für eine beginnende industrielle Rumproduktion. Als Vorbild diente die 1818 von einem gewissen Mr. Brine, einem englischen Händler, der auf Jamaika in der Zuckerraffinerie tätig gewesen war, errichtete Zucker- und Rumfabrik von Rhadamun. ${ }^{151}$ Russegger resümierte allerdings, dass der in den karibischen Kolonien hergestellte Rum wesentlich besser und günstiger sei. ${ }^{152}$

Da die Eisenverarbeitung noch rudimentär war, herrschte im Sudan nach wie vor die Notwendigkeit, Eisen- und Messingwaren aus Europa zu importieren. Die Klingen des im Sudan seit der Islamischen Expansion verbreiteten Schwerttyps Kaskara wurden seit dem 16. Jahrhundert mehrheitlich aus Europa importiert. ${ }^{153}$ Sehr gefragt waren österreichische zweischneidige Schwertklingen - Pallme zufolge besonders jene aus der im nordrhein-westfälischen Solingen ${ }^{154}$ liegenden Fabrik des österreichischen Schmieds Peter Küll. Dessen Schwerter hatten einen Totenkopf als Markenzeichen eingraviert. Messing- und Eisendraht aus Tirol waren ebenfalls gängige Tauschartikel. Barbiermesser aus der Steiermark fanden im Sudan nicht nur für die Rasur der Kopfhaare und des Intimbereichs Verwendung - „auch zur Excision der Mädchen und zur Verstümmelung der Knaben werden sie gebraucht"155.

Nachdem jahrhundertelang Kaurimuscheln das meistverbreitete Zahlungsmittel im afrikanisch-asiatischen Raum waren und europäische Kaufleute Milliarden von Kaurimuscheln in Umlauf gebracht hatten, kam es im 18. Jahrhundert zu einer Hyperinflation. ${ }^{156}$ Obwohl insbesondere seit der Eroberung des Sudan türkische und ägyptische Währungen sowie österreichische Maria-Theresien-Taler Eingang in den Handel gefunden hatten, blieb Tauschhandel vielerorts bedeutend. Nach der Hyperinflation der Kaurimuscheln wurden Glasperlen zum gängigen Tauschmittel. ${ }^{157}$ Pallme prognostizierte in seinem Reisebericht von 1843, dass der Handel mit Glasperlen, der ohnehin schon eine Hauptrolle in ganz Afrika spiele, weiter steigen werde. Deshalb war er über die Tatsache erstaunt, dass es nur zwei Glasfabriken gab. Afrikanische und asiatische Kaufleute seien gezwungen, die Glasperlen „aus der vierten und fünften Hand zu kaufen“158.

Europäische Schönheitsprodukte waren bei vielen Gesellschaften im Sudan Prestigeobjekte, mit denen sie sich von den anderen Mitgliedern ihrer Gruppe abheben konn-

150 Brehm, Reiseskizzen, Bd. 1, S. 199.

151 Prokesch, Erinnerungen, Bd. 2, S. 190; Russegger, Reisen, Bd. 2/1, S. 88.

152 Russegger, Reisen, Bd. 2/1, S. 88-89.

153 Christopher Spring, African arms and armour, Washington 1993, S. 41-42.

154 Zur Einbettung der Solinger Messer-, Schwerter-, und Säbelschmieden in den Kolonialhandel: Angelika Epple, Globale Machtverhältnisse, lokale Verflechtungen. Die Berliner Kongokonferenz, Solingen und das Hinterland des kolonialen Waffenhandels, in: Christof Dejung/Martin Lengwiler (Hrsg.), Ränder der Moderne. Neue Perspektiven auf die Europäische Geschichte (1800-1930) (Peripherien. Neue Beiträge zur Europäischen Geschichte 1), KölnWeimar-Wien 2016, S. 65-91.

155 Pallme, Beschreibung von Kordofan, S. 184.

156 Anirban Biswas, Money and Markets from Pre-colonial to Colonial India, Neu-Delhi 2007, S. 143-162.

157 Brehm, Reiseskizzen, Bd. 3, S. 98.

158 Pallme, Beschreibung von Kordofan, S. 185. 
ten. Zwar gab es in Ägypten eine beginnende Kosmetikindustrie, der Großteil wurde aber nach wie vor aus Europa eingeführt. So berichtet Pallme davon, dass österreichisches Antimonium, zu Pulver zerstoßen, von sudanesischen Frauen zum Schminken der Augenlider verwendet wurde. ${ }^{159}$ Parfums waren im Sudan ausschließlich höheren Bevölkerungsschichten vorbehalten, da sie sehr teuer waren. Russegger erwähnt auf Speik basierte Parfums, die damals im Umlauf waren. Kölnisch Wasser, das vereinzelt auf den Bazaren erworben werden konnte, war Teil eines diplomatischen Geschenks, das Konstantin Reitz der Tante König Husseins von Darfur, Prinzessin Soakim, zukommen ließ. ${ }^{160}$ Sehr begehrt waren außerdem europäische Seifen, insbesondere Speikseifen aus Kärnten. Pallmes Bericht zufolge musste jede Frau sie haben, „sonst hat sie das Recht sich scheiden zu lassen"161. Die Nachfrage war so groß, dass der Generalgouverneur des Sudan, Ahmad Pasha Abū Widān, von einem deutschen Unternehmer namens Bauer in Kamlin am Blauen Nil eine Seifenfabrik errichten ließ - als Hansal das Gebiet im Jahr 1855 bereiste, befand sie sich allerdings bereits im Verfall. ${ }^{162}$

\subsection{Der Nil, das Rote Meer und die Karawanen. Routen für den Handel}

Auch wenn der Sudan als Rohstofflieferant und Absatzmarkt erschlossen werden würde, stellte sich die wichtige Frage, wie die Waren vom Sudan nach Österreich und umgekehrt transportiert werden könnten.

Nach der Eroberung des Sudan wurden die wichtigsten Rohstoffe sofort dem staatlichen Monopol unterworfen, wodurch es den Händlern strikt verboten wurde, ihre Produkte an Privathändler zu veräußern. Durch dieses System konnte der ägyptische Vizekönig die Preise diktieren - ein Gewinn, wenn nicht auf illegalem Wege, war für lokale Händler kaum zu erwirtschaften, wie die besprochenen Elfenbeinlieferungen an die Rotmeerküste belegen. ${ }^{163}$ Zwar wurden im britisch-osmanischen Vertrag von Balta Liman (1838), dem später auch Österreich beitrat, den europäischen Mächten uneingeschränkter Zugang zu den Märkten des Osmanischen Reichs sowie gleiche Besteuerung eingeräumt, doch der Sudan gehörte staatsrechtlich nicht zum Osmanischen Reich und somit konnte Generalgouverneur Abd al-Latif Pascha Abd Allah (circa 1805-1883) den Handel fast uneingeschränkt kontrollieren. ${ }^{164}$ Russegger äußerte seine Hoffnung auf Abschaffung des Monopols im Sudan, ${ }^{165}$ die auf Druck des k. u. k. Konsuls von Khartum, Konstantin Reitz, zusammen mit der Absetzung Latif Paschas 1852

159 Pallme, Beschreibung von Kordofan, S. 184.

160 Brehm, Reiseskizzen, Bd. 3, S. 270.

161 Pallme, Beschreibung von Kordofan, S. 184.

162 Imhof, Fortsetzung der neuesten Briefe, S. 97-98.

163 Als der Vizekönig dieser illegalen Transporte gewahr wurde, erwarb er 1846 von Sultan Abdülmecid I. (18231861) die am Roten Meer liegenden Städte Massawa und Sawakin in einem Pachtvertrag: Jonathan Miran, Red Sea Citizens. Cosmopolitan Society and Cultural Change in Massawa, Bloomington 2009, S. 4. 
durchgesetzt werden konnte. ${ }^{166}$ Dennoch blieb ein Großteil des Handels in den Händen der Regierung, konstatierte Brehm. ${ }^{167}$

Zentrale Handelsroute für die Achse Sudan-Österreich war der Nil, der vom Delta bis Assuan durchgängig schiffbar war. Für die Nilroute taten sich aber einige Schwierigkeiten auf: linerseits die hohen Zollabgaben, andererseits die Nilkatarakte, die sich südlich von Assuan an vielen Stellen auftürmten. Russegger gab zu bedenken, dass die Regierung „noch viel mehr gewinnen würde, wenn sie bei mässigern Zöllen die Konkurrenz frei geben und dadurch die Produktion vervielfachen würde" ${ }^{\prime \prime 68}$. Um diesem Problem zu begegnen, wurden von sudanesischen wie von europäischen Händlern Versuche unternommen, eine Senkung der Zölle zu erwirken. Insbesondere das 1850 gegründete k. u. k. Konsulat Khartum konnte in dieser Beziehung einige Vorteile für europäische Händler durchsetzen. Bezüglich der Schiffbarmachung des Nils erwähnte Prokesch, dass der Vizekönig bereits Versuche unternommen hatte, die Katarakte zu sprengen. Sinnvoller sei allerdings der Bau eines Kanals. ${ }^{169}$ In den meisten Fällen entschieden sich die Handelstreibenden allerdings für die Karawanenroute durch die Nubische Wüste, die den großen Nilbogen durchschnitt. Dieser Weg beanspruchte laut Russegger sechzig bis neunzig Tage. ${ }^{170}$ Da in Österreich die Überzeugung vorlag, der Nil wäre südlich von Assuan nicht schiffbar, entschloss sich Reitz im Sommer 1852 für eine spektakuläre Aktion: Er kaufte aus eigener Kasse rund zweihundert Tiere, die er Kaiser Franz Joseph I. schenkte und mit einem Schiff von Khartum nach Alexandria bringen ließ. Die Tierfracht wurde in den Tiergarten Schönbrunn transportiert, wo der Sudan über Nacht zum Gesprächsthema wurde. ${ }^{171}$

Der Weiße Nil sowie seine Zuflüsse waren bis weit in den Süden schiffbar. Nach der Durchsetzung der Handelsfreiheit im Jahr 1851 durchdrangen immer größere Gruppen von Händlern dieses Gebiet, die größten davon waren aber nach wie vor die einmal jährlich organisierten Expeditionen der Regierung, die von europäischen Händlern wie Nikola Ulivi (circa 1807-1852) aus Sardinien und Antoine Brun-Rollet (1810-1858) aus Savoyen geleitet wurden. Heuglin berichtete von „blutigen Zusammenstössen“, die durch die „Brutalität der Händler“ gegenüber den „im Ganzen wirklich harmlosen Eingebornen" provoziert wurden. ${ }^{172}$ Auch der Missionar Ignaz Knoblecher aus St. Kanzian,

166 Roemheld, Konstantin Reitz, S. 312

167 Brehm, Reiseskizzen, Bd. 1, S. 196-197.

168 Russegger, Reisen, Bd. 2/2, S. 36.

169 Prokesch, Erinnerungen, Bd. 2, S. 170-171.

170 Russegger, Reisen, Bd. 2/1, S. 410.

171 Christa Riedl-Dorn, Hohes Tier. Die Geschichte der ersten Giraffe in Schönbrunn, Wien 2008, S. 112-113.

172 Heuglin berichtete davon, dass europäische, ägyptische und türkische Kaufleute dazu übergingen, Elfenbein mit Gewalt zu entwenden, als die lokale Bevölkerung Glasperlen nicht mehr als Tauschobjekt annehmen wollte. Zudem stiegen einige Expeditionsteilnehmer auch in den Sklavenhandel ein. Die Gewaltbereitschaft der Kaufleute führte dazu, dass sich die lokale Bevölkerung gegen die „Marodeurs“ zu wehren begann. Dies wiederum veranlasste die Organisatoren der Expeditionen dazu, die Nilbarken mit bewaffneten Schutzmannschaften auszustatten, sodass zwischen vierzig und hundert Askari (arab. "Soldaten“) die Elfenbeinjagden begleiteten. Mit zahlreichen als Zeribah bezeichneten Niederlassungen bildeten europäische, ägyptische und türkische Handelsleute ein eng verzweigtes Netz an Stützpunkten, um sich Zugriff auf Handelsrouten zu verschaffen, die bis in das zentralafrikanische und kongolesische Gebiet reichten. Als Heuglin das Gebiet 1861 bereiste, sollen bis zu dreihundert Soldaten in einer einzelnen Zeribah stationiert gewesen sein: Heuglin, Reise in das Gebiet des Weissen Nil, S. 12-18. Ignaz Pallme legte ebenfalls eine ausführliche Beschreibung der Sklavenjagden von 1838 
der die unter österreichischem Schutz stehende katholische Mission in Zentralafrika leitete, bereiste mehrmals das Gebiet des Weißen Nils mit seinem Dampfboot Stella matutina, wobei mit Gondokoro und Heiligenkreuz zwei Missionsstationen im Territorium der Bari errichtet wurden. ${ }^{173}$ Auch der Blaue Nil war damals bis weit in den Süden schiffbar, blieb aber laut Russegger "ein schlaffer Nerv, den die ägyptische Regierung nach vollen 24 Jahren des Besitzes und ausschließlicher Alleinherrschaft noch nicht zu beleben verstand"174.

Als wichtigstes Lasttier galt das Kamel. Allerdings litten diese Tiere in den tropischen Zonen des Sudan unter einer Fliegenart, die bereits 1791 vom schottischen Afrikareisenden James Bruce (1730-1794) beschrieben worden war ${ }^{175}$ und nicht selten dazu beitrug, dass ganze Karawanen zugrunde gingen. ${ }^{176}$ Deshalb regte Russegger an, südlich der Wüstengebiete Esel zu verwenden. ${ }^{177}$

Die im Sudan tätigen Händler und das Konsulat von Khartum waren bestrebt, den Handel mit den Nachbargebieten zu beleben. Das Sultanat von Darfur kappte unter Sultan Muhammad Hussein ibn Muhammed Fadl (reg. 1838-1873) die Karawanenroute nach Dongola, sodass lediglich die Route nach Asiut blieb, entlang welcher lediglich einmal pro Jahr eine Karawane unterwegs war - viel zu wenig, um einen intensiven Handel mit Zentralafrika zu betreiben. ${ }^{178}$ Die im August 1851 in Khartum weilende Prinzessin Soakim, die Tante des Sultans, befand sich auf Pilgerreise nach Mekka. Diese Gelegenheit wollte Reitz nutzen, um diplomatische Kontakte zum Sultanat von Darfur anzubahnen und über die Wiederherstellung des Handels in den Sudan zu verhandeln. Nach einer Audienz wurde Reitz eine diplomatische Reise in Aussicht gestellt. Zu einer solchen Reise nach Darfur, dem Knotenpunkt für den Karawanenhandel in das zentralafrikanische Gebiet und in den westlichen Tschad, kam es aber nie. ${ }^{179}$ Pallme legte große Hoffnungen in den Onkel des Sultans, Abu Madyan († circa 1847), den er in seinen Kolonialplan ${ }^{180}$ integrierte: Nach der geplanten Eroberung Darfurs wäre Abu Madyan den Plänen Pallmes zufolge nach Österreich zu bringen, „wo er sich mit einem anständigen Gehalte begnügen und auf den Thron von Darfur verzichten würde"181. Diese hochtrabenden Vorstellungen von einer kolonialen Inbesitznahme Darfurs wurden allerdings kaum mit Aufmerksamkeit bedacht.

und 1839 vor, die im British and Foreign Anti-Slavery Reporter veröffentlicht wurde: Pallme, Beschreibung von Kordofan, S. 188-212. Zur Einordnung der Elfenbeinjagden: Sauer, Schwarz-Gelb in Afrika, S. 34-36, 43.

173 Markus Kaiserseder, Die österreichischen Missionsstationen im Sudan zur Mitte des 19. Jahrhunderts. Wegbereiter eines Kolonialismus?, Dipl. Wien 2013, S. 63-76.

174 Russegger, Reisen, Bd. 2/2, S. 491.

175 James Bruce, Travels to Discover the Source of the Nile, Bd. 5, London 1790, S. 188-192.

176 Russegger, Reisen, Bd. 2/2, S. 155-156.; Pallme, Beschreibung von Kordofan, S. 74-75.

177 Russegger, Reisen, Bd. 2/2, S. 156-157

178 Für diese Route veranschlagte Prokesch 38 Tage: Prokesch, Erinnerungen, Bd. 2, S. 160.

179 Roemheld, Konstantin Reitz, S. 314.

180 Ignaz Pallmes „Pläne und Vorarbeiten zur Eroberung von Abissinien, Darfur und Tripolis für Österreich; nebst Bemerkungen über den Schwerpunkt der Kanonenkugel" sind abgedruckt in Zach, Ignaz Pallme, S. 103-109.

181 Zach, Ignaz Pallme, S. 108. 


\section{Fazit}

Der Sudan, der von österreichischen Reisenden noch vor dem Scramble for Africa inspiziert wurde, war für Handelstreibende eine attraktive und zukunftsträchtige Region, die aufgrund ihrer Bodenschätze für koloniale Akteur*innen die Hoffnung auf vielversprechende Gewinne in sich barg. Russegger, der im Zuge seiner Expedition zwar weder die legendären Mondberge noch die scheinbar unerschöpflichen Goldvorkommen finden konnte, entfachte durch seine Reiseberichte das Interesse einiger österreichischer Handelstreibender auf dieses neue, von Europäer*innen bisher beinahe unberührte Gebiet. Immer mehr Kaufleute kamen in den Sudan und hielten dort Ausschau nach günstigen Rohstoffen für die heimische Industrie. Auch als Absatzgebiet für Produkte aus Österreich kam der Sudan infrage. Erst durch diese Handelsreisenden der ersten Stunde wurden die staatlichen Stellen auf den Sudan aufmerksam.

Es lassen sich drei Hauptgründe dafür anführen, warum sich Österreicher*innen überhaupt auf ein Engagement im Sudan einließen: 1. Die Habsburgermonarchie hatte bereits seit Mitte des 17. Jahrhunderts versucht, den Handel mit dem Osmanischen Reich zu kontrollieren und in diesem Kontext auch die Verbindungen zu Ägypten und der Levante zu intensivieren. 2. Ein begünstigender Faktor mag zudem die ägyptische Expansion nach Süden gewesen sein - der Sudan war bereits militärisch erschlossen und eine rudimentäre Verwaltung aufgebaut worden, ohne dass die Habsburgermonarchie zu den Waffen hätte greifen müssen. Zudem war im neueroberten Gebiet noch keine europäische Macht vertreten. Dieser Umstand begünstigte die Errichtung des Konsulats, da keine politischen Verwicklungen mit anderen Kolonialmächten zu befürchten waren. Ein 3. Aspekt ist in dem von den Briten durchgesetzten Vertrag von Balta Liman zu sehen, in dessen Windschatten sich den Akteur*innen der Habsburgermonarchie im Sudan völlig neue Handlungsspielräume eröffneten.

Die eingangs aufgestellte These, wonach das Konsulat von Khartum und die im Sudan lebenden Menschen aus den Ländern der Habsburgermonarchie ein - wenn auch zeitlich und räumlich begrenztes - „informal empire“ errichteten, kann bestätigt werden. Da die Reiseberichte über einen Zeitraum von circa 35 Jahren verstreut sind, kann der Prozess von den anfänglichen Expeditionen bis zur Errichtung einer konsularischen Präsenz und der effektiven Durchsetzung von Herrschaft anschaulich nachgezeichnet werden. Mit dem k. u. k. Konsulat von Khartum, dessen Gründung im Jahr 1850 mit dem Richtungswechsel in der österreichischen Handelspolitik unter der Regie von Handelsminister Bruck zusammenhängt, verfügte die Habsburgermonarchie über ein Instrument, das durchaus bestimmenden Einfluss auf lokale Autoritäten ausüben konnte. Die Österreicher*innen im Sudan beteiligten sich an der für ein „informal empire“ typischen Praxis der ungleichen Verträge. ${ }^{182} \mathrm{Zu}$ den Indikatoren für die Herrschaftspraxis eines von den k. u. k. Behörden betriebenen „informal empire“ im Sudan zählen ferner die Absetzung des Provinzialgouverneurs, die erzwungene Öffnung weiter Gebiete für den Handel, das Gegeneinander-Ausspielen von Bevölkerungsgruppen, Zivilisierungs- 
und Missionierungsfantasien, die Ausbeutung von Ressourcen und die Elfenbeinjagden mit den Gewaltexzessen gegen die lokale Bevölkerung.

Dass die Habsburgermonarchie nicht auf die Dauer Einfluss auf den Sudan nehmen konnte, ist auf mehrere Faktoren zurückzuführen. Ein wesentliches Hindernis, das sich den Händlern in den Weg stellte, war neben dem Monopolsystem des Vizekönigs die Unzugänglichkeit bestimmter Gebiete durch die mangelnde Schiffbarkeit des Nils. Zudem fehlte der Habsburgermonarchie eine schlagkräftige Handels- und Kriegsmarine, die für die Etablierung kolonialer und imperialer Herrschaft im 19. Jahrhundert eine conditio sine qua non gewesen wäre. ${ }^{183}$ Auf dem Nil waren nur sehr einfache, hölzerne Nilbarken verfügbar. So muss die vom Konsulat betriebene Politik als „Kanonenbootdiplomatie" ohne Kanonenboote bezeichnet werden. Diese Formulierung soll aber nicht über die Tatsache hinwegtäuschen, dass auch österreichische Akteur*innen aktiv an der Organisierung und Durchführung der oftmals in Gewaltakte gegen die lokale Bevölkerung ausartenden Elfenbeinjagden beteiligt waren. Die Partizipation im Handel mit Sklav*innen ist bisher nur für Franz Binder belegt und bleibt daher ein Forschungsdesiderat. ${ }^{184}$ Ein weiterer Grund für das Scheitern der Bemühungen im Sudan hängt damit zusammen, dass kolonialistische und imperialistische Ansätze nur in Teilen der Bevölkerung genügend Rückhalt hatten, z. B. im maritimen Interessenskomplex von Triest, in der schmalen Schicht von Großindustriellen und unter einzelnen Bürger*innen, die auf der Suche nach Abenteuern und Gewinn in den Sudan ziehen wollten.

Letztlich muss der Bedeutungsverlust der österreichischen Vertretung im Sudan auch im Kontext der Ausweitung britischer und französischer Herrschaft in Afrika gesehen werden. Das British Empire konnte auf dem Seeweg nach Indien den ostafrikanischen Raum durchdringen und trat als dominante wirtschaftliche und politische Macht im Indischen Ozean auf. Frankreich suchte die britische Hegemonie zu brechen, indem in Verhandlungen mit Ägypten die Konzession für das Kanalbauprojekt von Suez erlangt wurde. Das Vereinigte Königreich befürchtete, dass damit andere Seemächte die britische Hegemonie im Indischen Ozean brechen würden. ${ }^{185}$ Der ohnehin schon mit vielen Schwierigkeiten verbundene Handel auf der Nilroute, den Reitz und seine Nachfolger entwickeln wollten, sank mit der Eröffnung des Suezkanals endgültig in die Bedeutungslosigkeit ab. Lediglich die Bereitschaft Hansals, das Konsulat ehrenamtlich weiterzuführen, verhinderte eine Schließung.

Es kann festgehalten werden, dass die Österreicher*innen vor Ort durch ihr persönliches Agieren die Handelsaktivitäten zwischen dem Sudan und der Habsburgermonarchie maßgeblich beeinflussten - wenn auch in einem kleinen Rahmen, der von der Begrenztheit der finanziellen Ressourcen bestimmt war. Der Sudan stellte für die meisten politischen Entscheidungsträger ein Phänomen dar, mit dem sie sich - wenn

\footnotetext{
183 Weingartshofer, Imperialismus-Strategien, S. 126-127.

184 Endre Stiansen, Franz Binder. Ein europäischer Araber im Sudan, in: Walter Sauer (Hrsg.), k. u. k. kolonial. Habsburgermonarchie und europäische Herrschaft in Afrika, Wien-Köln-Weimar 2002, S. 111-126.

185 Sauer, Schwarz-Gelb in Afrika, S. 29-32.
} 
überhaupt - nur am Rande beschäftigten. Die Habsburgermonarchie hatte ohnehin alle Hände voll zu tun und war darauf bedacht, gute Beziehungen zum Osmanischen Reich zu pflegen, die Spannungen auf dem Balkan zu beruhigen, den Verlust Norditaliens zu kompensieren sowie den Konflikt mit Preußen zu lösen. ${ }^{186}$

\section{Quellen}

Brehm, Alfred Edmund, Reiseskizzen aus Nord-Ost-Afrika oder den unter egyptischer Herrschaft stehenden Ländern Egypten, Nubien, Sennahr, Rosseeres und Kordofahn, gesammelt auf seinen in den Jahren 1847 bis 1852 unternommenen Reisen, 3 Bde., Jena 1855.

Bruce, James, Travels to Discover the Source of the Nile, Bd. 5, London 1790.

Hartmann, Carl Friedrich Alexander, Handwörterbuch der Mineralogie, Berg-, Hüttenund Salzwerkskunde, Bd. 2, IImeau 1825.

Heuglin, Theodor von, Reisen in Nord-Ost-Afrika. Tagebuch einer Reise von Chartum nach Abyssinien mit besonderer Rücksicht auf Zoologie und Geographie unternommen in dem Jahre 1852 bis 1853. Mit einer Karte, einem Gebirgs-Durchschnitte und 3 Bildern, Gotha 1857.

Ders., Reise in das Gebiet des Weissen Nil und seiner westlichen Zuflüsse in den Jahren 1862-1864, Leipzig-Heidelberg 1869.

Holt, Peter Malcom (Hrsg.), The Sudan of the Three Niles. The Funj Chronicle 9101288/1504-1871 (Islamic history and civilization. Studies and texts 26), Leiden-BostonKöln 1999.

Imhof, Franz Xaver (Hrsg.), Neueste Briefe aus Chartum in Central-Afrika, geschrieben von Martin Hansal, gewesenem Lehrer an der Pfarrhauptschule zu Maria Geburt am Rennwege in Wien, derzeit Lehrer der Negerjugend und Sekretär des hochwürdigen Herrn Pro-Vikars Dr. Knoblecher, Chefs der katholischen Mission für Mittel-Afrika zu Chartum, an seinen Freund Franz Xaver Imhof, Lehrer an der Pfarrhauptschule zu Maria Geburts am Rennwege in Wien, Wien 1855.

Ders. (Hrsg.), Fortsetzung der neuesten Briefe aus Chartum in Central-Afrika, geschrieben von Martin Hansal, gewesenem Lehrer an der Pfarrhauptschule zu Maria Geburt am Rennwege in Wien, derzeit Lehrer der Negerjugend und Sekretär des hochwürdigen Herrn Pro-Vikars Dr. Knoblecher, Chefs der katholischen Mission für Mittel-Afrika zu Chartum, Wien 1856.

Pallme, Ignaz, Beschreibung von Kordofan und einigen angränzenden Ländern nebst einem Ueberblick über den dasigen Handel, die Sitten und Gebräuche der Einwohner und die unter der Regierung Mehemed Alis stattgefundenen Sklavenjagden, StuttgartTübingen 1843.

186 Weingartshofer, Imperialismus-Strategien, S. 139-140. 
Russegger, Joseph, Reisen in Europa, Asien und Afrika, mit besonderer Rücksicht auf die naturwissenschaftlichen Verhältnisse der betreffenden Länder, 7 Bde., Stuttgart $1841-1849$

\section{Literatur}

Agstner, Rudolf, Das k.k. (k.u.k.) Konsulat für Central-Afrika in Khartoum 1850-1885, Kairo 1993.

Becker, Felicitas, Netzwerke vs. Gesamtgesellschaft: ein Gegensatz? Anregungen für Verflechtungsgeschichte, in: Geschichte und Gesellschaft 30 (2004), Heft 2, S. 314-324.

Beckert, Sven, King Cotton. Eine Geschichte des globalen Kapitalismus, München 2019. Biswas, Anirban, Money and Markets from Pre-colonial to Colonial India, Neu-Delhi 2007.

Colloseus, Gerald, Ein österreichisches Schicksal? Analyse von Kolonialprojekten am Beispiel der Mission Tegetthoffs und Heuglins ins Rote Meer 1857/58, Dipl. Wien 2008.

Deutsch, Engelbert, Die effektiven Konsuln Österreich (-Ungarns) von 1825-1918. Ihre Ausbildung, Arbeitsverhältnisse und Biografien, Wien-Köln-Weimar 2017.

Elles, R. J., The Kingdom of Tegali, in: Sudan Notes and Records 18 (1935), S. 1-35.

Epple, Angelika, Globale Machtverhältnisse, lokale Verflechtungen. Die Berliner Kongokonferenz, Solingen und das Hinterland des kolonialen Waffenhandels, in: Christof Dejung/Martin Lengwiler (Hrsg.), Ränder der Moderne. Neue Perspektiven auf die Europäische Geschichte (1800-1930) (Peripherien. Neue Beiträge zur Europäischen Geschichte 1), Köln-Weimar-Wien 2016, S. 65-91.

Fahmy, Khaled, Mehmed Ali. From Ottoman Governor to Ruler of Egypt, Oxford 2008.

Fischer, Robert-Tarek, Österreich im Nahen Osten. Die Großmachtpolitik der Habsburgermonarchie im Arabischen Orient 1633-1918, Wien-Köln-Weimar 2006.

Frank, Alison, Continental and Maritime Empires in an Age of Global Commerce, in: East European Politics and Societies 25 (2011), Heft 4, S. 779-784.

Gritsch, Mario, Die Beziehungen Österreich-Ungarns zum ägyptischen Sudan. Die staatlichen, kirchlichen sowie privaten Interessen und Unternehmungen in diesem Raume, phil. Diss. Wien 1975.

Hagen, Thomas J., Österreichs Mitteleuropa 1850-1866. Die Wirtschafts-, Währungsund Verkehrsunion des Karl Ludwig Freiherrn von Bruck (Historische Studien 507), Husum 2015.

Hamann, Christof/Honold, Alexander, Der Kilimandscharo, in: Jürgen Zimmerer (Hrsg.), Kein Platz an der Sonne. Erinnerungsorte der deutschen Kolonialgeschichte, Frankfurt a. M. 2013, S. 81-95. 
Hassinger, Hugo, Österreichs Anteil an der Erforschung der Erde. Ein Beitrag zur Kulturgeschichte Österreichs, Wien 1949.

Hill, Richard, Egypt in the Sudan 1820-1881, London 1959.

Jandl, Gerhard „, Österreichs Name ist der wohlklingendste im ganzen Sudan“. Die Österreichische Mission in Zentralafrika (1848-1916) und die Beteiligung von katholischen Couleurstudenten (Tradition und Zukunft 17), Wien 2019.

Kaiserseder, Markus, Die österreichischen Missionsstationen im Sudan zur Mitte des 19. Jahrhunderts. Wegbereiter eines Kolonialismus?, Dipl. Wien 2013.

Krobb, Florian, "The starting point for the civilisation of the Dark Continent." Austrians in the Sudan: Ernst Marno and Rudolf Slatin as Agents of African Conquest, in: Austrian Studies 20 (2012), S. 142-160.

Miran, Jonathan, Red Sea Citizens. Cosmopolitan Society and Cultural Change in Massawa, Bloomington 2009.

Osterhammel, Jürgen, Kolonialismus. Geschichte - Formen - Folgen, München 1995.

Ders., Die Verwandlung der Welt. Eine Geschichte des 19. Jahrhunderts, München 2016.

Owen, Roger, Egypt and Europe. From French expedition to British occupation, in: Roger Owen/Bob Sutcliffe (Hrsg.), Studies in the theory of imperialism, London 1972, S. 195-209.

Reinhard, Wolfgang, Die Unterwerfung der Welt. Globalgeschichte der europäischen Expansion 1450-2015, München 2016.

Riedl-Dorn, Christa, Hohes Tier. Die Geschichte der ersten Giraffe in Schönbrunn, Wien 2008 .

Roemheld, Friedrich, Konstantin Reitz. Ein vergessener Vorkämpfer für abendländische Kultur in Afrika, in: Mitteilungen des Österreichischen Staatsarchivs 12 (1959), S. 289-373.

Sanderson, George Neville, British Informal Empire, Imperial Ambitions, Defensive Strategies, and the Anglo-Portuguese Congo Treaty of February 1884, in: Stig Förster/Wolfgang J. Mommsen/Ronald Robinson (Hrsg.), Bismarck, Europe, and Africa. The Berlin Africa Conference 1884-1885 and the Onset of Partition, London 1988, S. 189-214.

Sauer, Walter, Schwarz-Gelb in Afrika. Habsburgermonarchie und koloniale Frage, in: Walter Sauer (Hrsg.), k. u. k. kolonial. Habsburgermonarchie und europäische Herrschaft in Afrika, Wien-Köln-Weimar 2002, S. 17-78.

Ders., Auf dem Weg zu einer Kolonialgeschichte Österreichs, in: Österreich in Geschichte und Literatur 55 (2011), Heft 1, S. 2-6.

Ders., Ein Jesuitenstaat in Afrika? Habsburgische Kolonialpolitik in Ägypten, dem Sudan und Äthiopien in der ersten Hälfte des 19. Jahrhunderts, in: Österreich in Geschichte und Literatur 55 (2011), Heft 1, S. 7-27. 
Slokar, Johann, Geschichte der österreichischen Industrie und ihrer Förderung unter Kaiser Franz I. Mit besonderer Berücksichtigung der Großindustrie und unter Benützung archivalischer Quellen, Wien 1914.

Spring, Christopher, African arms and armour, Washington 1993.

Strohmeyer, Arno, "Österreichische“ Geschichte der Neuzeit als multiperspektivische Raumgeschichte, in: Martin Scheutz/Arno Strohmeyer (Hrsg.), Was heißt „Österreichische" Geschichte? Probleme, Perspektiven und Räume der Neuzeitforschung (Wiener Schriften zur Geschichte der Neuzeit 6), Innsbruck-Wien-Bozen 2008, S. 167-197.

Weingartshofer, Philipp, Imperialismus-Strategien am Beispiel der Österreicher im Sudan. Das Zusammenspiel kolonialer Akteure in Peripherie und Metropole am Beispiel der Österreicher im Sudan im 19. Jahrhundert, phil. Dipl. Wien 2013.

Wendt, Reinhard, Vom Kolonialismus zur Globalisierung. Europa und die Welt seit 1500, Paderborn-München-Wien-Zürich 2007.

Wenzlhuemer, Roland, Globalgeschichte schreiben. Eine Einführung in 6 Episoden, Konstanz-München 2017.

Zach, Michael, Österreicher im Sudan von 1820 bis 1914, Wien 1985.

Ders., Ignaz Pallme. Ein unbekannter Kolonialentwurf für Nordostafrika aus dem Jahr 1851, in: Walter Sauer (Hrsg.), k. u. k. kolonial. Habsburgermonarchie und europäische Herrschaft in Afrika, Wien-Köln-Weimar 2002, S. 79-110.

Florian Ambach studiert Geschichte und Deutsch an der Universität Innsbruck. Florian.Ambach@student.uibk.ac.at

\section{Zitation dieses Beitrages}

Florian Ambach, Baumwolle, Elfenbein und Glasperlen. Perspektiven österreichischer Reisender auf die Errichtung eines „informal empire“ im Sudan des 19. Jahrhunderts, in: historia.scribere 13 (2021), S. 203-231, [http://historia.scribere.at], eingesehen 22.6.2021 (=aktuelles Datum).

Creative Commons Licences 3.0 Österreich unter Wahrung der Urheberrechte der Autorlnnen. 
